\title{
Analysis of rotation sensor data from the SINAPS@ Kefalonia (Greece) post-seismic experiment-link to surface geology and wavefield characteristics
}

\author{
Sarah Sbaa ${ }^{1}$, Fabrice Hollender ${ }^{1,2^{*}}$, Vincent Perron ${ }^{1}$, Afifa Imtiaz ${ }^{3}$, Pierre-Yves Bard ${ }^{2}$, Armand Mariscal ${ }^{2}$,
} Alain Cochard ${ }^{4}$ and Alain Dujardin ${ }^{1}$

\begin{abstract}
Although rotational seismology has progressed in recent decades, the links between rotational ground motion and site soil conditions are poorly documented. New experiments were performed on Kefalonia Island (Greece) following two large earthquakes $\left(M_{W}=6.0, M_{W}=5.9\right)$ in early 2014 on two well-characterized sites (soft soil, $V_{S 30} \sim 250 \mathrm{~m} / \mathrm{s}$; rock, $V_{S 30} \sim 830 \mathrm{~m} / \mathrm{s}, V_{S 30}$ being harmonic average shear-wave velocity between 0 and $30 \mathrm{~m}$ depth). These earthquakes led to large six-component (three translations and three rotations) datasets of hundreds of well-recorded events. The relationship between peak translational acceleration versus peak rotational velocity is found sensitive to the site conditions mainly for the rotation around the vertical axis (torsion; dominated by Love waves): the stiffer the soil, the lower the torsion, for a given level of translational acceleration. For rotation around the horizontal axes (rocking; dominated by Rayleigh waves), this acceleration/rotation relationship exhibits much weaker differences between soft and rock sites. Using only the rotation sensor, an estimate of the Love-to-Rayleigh energy ratios could be carried out and provided the same results as previous studies that have analyzed the Love- and Rayleigh-wave energy proportions using data from translational arrays deployed at the same two sites. The coupling of translational and rotational measurements appears to be useful, not only for direct applications of engineering seismology, but also to investigate the composition of the wavefield, while avoiding deployment of dense arrays. The availability of new, low-noise rotation sensors that are easy to deploy in the field is of great interest and should extend the use of rotation sensors and expand their possible applications.
\end{abstract}

Keywords: Rotational seismology, Wavefield characteristics, $V_{S 30}$, Site effects, Love wave, Rayleigh wave

\section{Introduction}

At present, the definition of seismic hazard involves almost exclusively translational ground-motion analysis along the three dimensions of space. However, to fully describe the ground motion, rotations also need to be considered, which results in a total of six components (i.e., three for translation and three for rotation; also known as the six degrees of freedom; 6-DOF). Rotations were not taken into account for a long time, as they were

\footnotetext{
${ }^{*}$ Correspondence: fabrice.hollender@cea.fr

${ }^{1}$ CEA, DEN, 13108 St Paul lez Durance, France

Full list of author information is available at the end of the article
}

considered as negligible (Richter 1958), and the same for their engineering consequences in comparison with those of translational motion. Moreover, rotation sensors were not available to directly measure rotations during an earthquake.

Over the past four decades, rotational seismology has caught the attention of many earthquake scientists. For example, Droste and Teisseyre (1976) derived rotations from an array of seismographs. Arrays of translational sensors (as standard accelerometers) were also used by Spudich et al. (1995) and Spudich and Fletcher (2008). Nigbor (1994) measured the rotation induced by a large chemical explosion using a gyro-sensor. Again using a 
gyro-sensor, and an inertial angular displacement sensor, Takeo (1998) measured the rotation rate in the near-field region of an earthquake swarm. Igel et al. (2005) and Igel et al. (2007) used a ring laser gyro to record rotational motions for large, long-distance events. The development of more compact (and cheaper) sensors based on electrochemical magnetohydrodynamic technology allowed easier field deployment, used, for example, by Liu et al. (2009), Wassermann et al. (2009), Yin et al. (2016), and Zembaty et al. (2017).

However, there remain very few datasets of rotational records, especially in comparison with the standard "translational" acceleration datasets. There is the dataset built by Takeo (2009) with the records of a seismic swarm in offshore Ito, Japan, and those built by Liu et al. (2009) in Taiwan, and Yin et al. (2016) at the Garner Valley Downhole Array (GVDA) in California, USA. The effects of the local soil conditions on rotations have not been directly addressed from the empirical and statistical points of view, especially due to the lack of large and diversified datasets, although these local soil conditions might have great impact on the translational seismic hazard levels, due to the importance of site effects, and on the rotational motion as well, in relation to the development of local surface waves.

Beyond the possible importance of rotation in earthquake engineering, the measurements of both rotation and translation might increase the possible applications in terms of wavefield composition analysis (i.e., part of the energy devoted to body or surface waves), derivation of the propagation velocity of seismic waves, source kinematics, and other aspects (Takeo and Ito 1997; Lee et al. 2009a; Igel et al. 2012; Marano and Fah 2014). The current limitation for the implementation of this approach is the relatively low sensitivity of previous rotation sensors that could be used in the field (like the Eentec R-1 we used in the present study), as these needed relatively high motion levels to provide an acceptable signal-to-noise ratio. However, a new generation of rotation sensors is now available, as, for example, the Eentec R-2 (Leugoud and Kharlamov 2012) or the BlueSeis3A (Bernauer et al. 2017), and these might allow new applications in the near future.

In this paper, we introduce two new 6-DOF datasets that were recorded on well-characterized sites with different subsoil properties, during the post-seismic sequence of the two large earthquakes $\left(M_{\mathrm{W}}=6.0\right.$ and $M_{\mathrm{W}}=5.9$ ) that occurred in early 2014 on the island of Kefalonia, in the Ionian Sea (Greece) (Hollender et al. 2015). This survey was conducted within the framework of the SINAPS@ program (Berge-Thierry et al. 2016). These new datasets are compared with the previously available datasets (Liu et al. 2009; Takeo 2009; Yin et al. 2016), and the relationships between translational acceleration and rotational velocity are discussed. Special attention will be paid to possible effects of the soil properties on translational acceleration versus rotational velocity correlations. We also analyze 6-DOF in terms of spectral ratios. Finally, we comment on the possible uses of rotation measurements to evaluate the ratio of the energy between Love and Rayleigh waves through comparisons with previous data obtained by translational sensor array analysis (Imtiaz 2015; Imtiaz et al. 2017).

In the earthquake engineering literature, the terms "acceleration" and "velocity" implicitly concern translational particle acceleration and velocity. In the present paper, we specifically specify "translational acceleration" and "translational velocity" to clearly distinguish these from "rotational velocity" The term "rotational rate" is also often used in the rotational seismology literature, although here the term "rotational velocity" is preferred. For the same purpose, the acronyms of "PGTA" (i.e., peak ground translational acceleration defined here as the maximum in the time domain of the absolute value of the translational acceleration along the three components) and "PGRV" (i.e., peak ground rotational velocity, similarly defined as the maximum in the time domain of the absolute value of the rotational velocity along the three components) are used.

\section{The SINAPS@ Kefalonia-Argostoli test site}

Kefalonia Island is located in the Ionian Sea, Greece (Fig. 1), and it is one of the most seismically active regions in the Euro-Mediterranean area. This is particularly due to the proximity of the Kefalonia Transform Fault, which has a major role in the transition zone between the African subducting plate and the continental Apulian plate (see, e.g., Louvari et al. 1999). Due to this high seismicity and the presence of a sedimentary basin, this area was chosen as a test site within the framework of the French National Research Agency PIA SINAPS@ project (www. institut-seism.fr/projets/sinaps/, Berge-Thierry et al. 2016). A permanent accelerometric vertical network within the Koutavos basin, known as "Argonet," has been installed with the long-term objective to perform the validation of three-dimensional, nonlinear computer codes (the notion of code validation being the quantitative comparison of the recorded ground motions with their numerical predictions, see, e.g., Maufroy et al. 2015).

The Koutavos basin is situated south of the town of Argostoli, the capital of the island. It is located on the southern shore of an elongated lagoon and is filled with Quaternary and Pliocene detritic deposits. This basin forms the heart of an active syncline (i.e., the Argostoli syncline) that is oriented NNW-SSE (Fig. 1) and is situated at the east of the thrusts that are associated with 


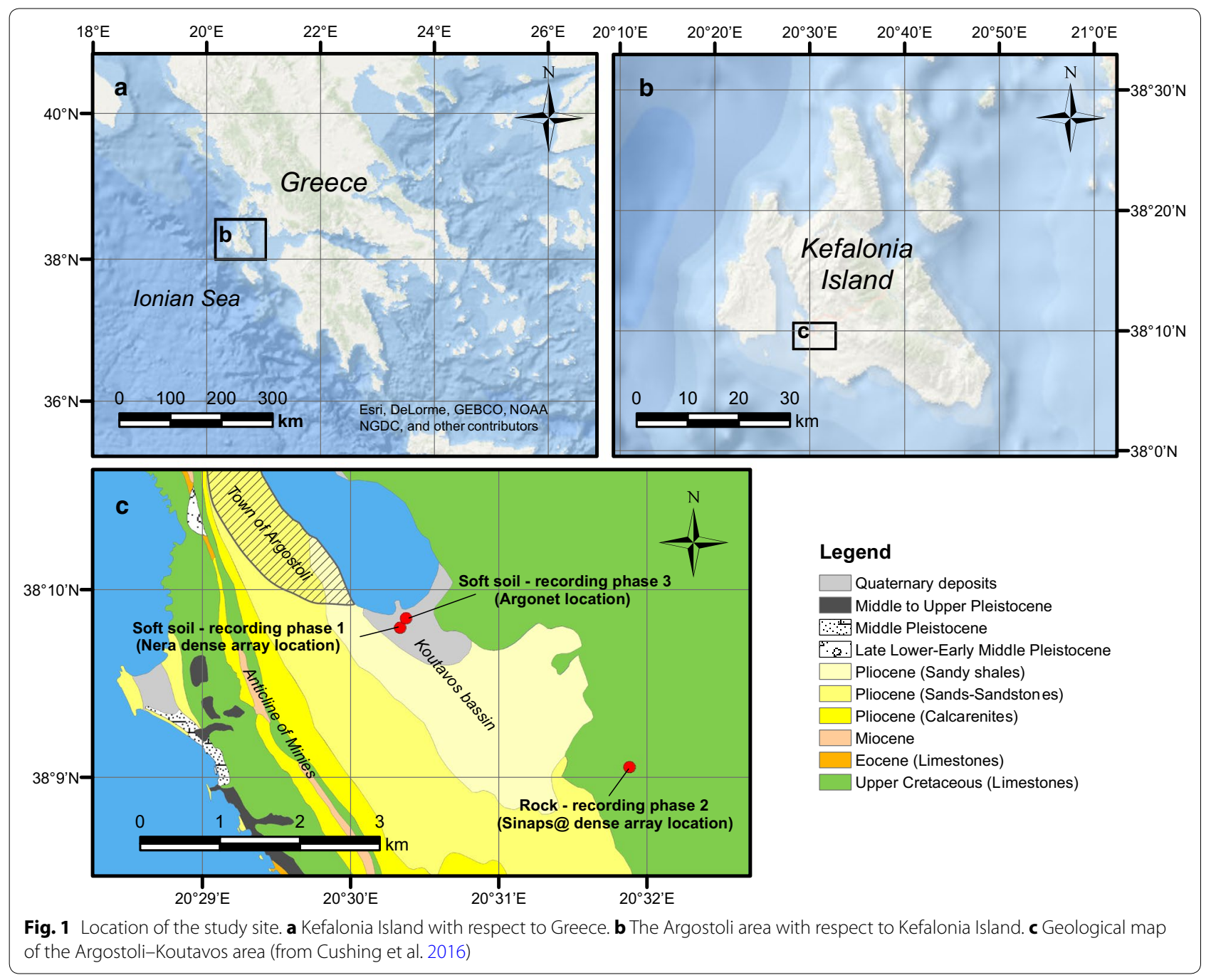

the asymmetric anticline of Minies. These folds distort a series of extremely thick Cretaceous limestone (from the lower Cretaceous), and they are topped off locally by a carbonate Eocene to Paleocene series and then a detritic Oligocene to Miocene series. This first folded series is overlain by a detritic series composed of calcarenite and then argillite and sandstone, which goes from the lower Pliocene to the Quaternary. The Plio-Quaternary series is also folded, and the deformation of the old Quaternary to middle Pliocene certifies the steadiness of the compressive deformation.

The sites where the rotation data presented in this paper were recorded have been characterized by geophysical methods based on analysis of the surface-wave dispersion characteristics. In addition, cross-hole and down-hole measurements were carried out within the Koutavos park (Cushing et al. 2016). This survey led to the determination of the $V_{\mathrm{S} 30}$ measures (i.e., the harmonic mean of the shear-wave velocities over the $30 \mathrm{~m}$ of soil), as: $V_{\mathrm{S} 30} \sim 250 \mathrm{~m} / \mathrm{s}$ for the soft-soil sites and $V_{\mathrm{S} 30} \sim 830 \mathrm{~m} / \mathrm{s}$ for the rock sites.

Before the installation of the permanent vertical accelerometric array that has been operational since July 2015, Kefalonia Island was shaken by two significant earthquakes, on January 26, 2014, at 13:55:43 UTC $\left(M_{\mathrm{L}}=5.8\right.$, $M_{\mathrm{W}}=6.0$, according to the National Observatory of Athens seismicity catalog), and on February 3, 2014, at 03:08:45 UTC $\left(M_{\mathrm{L}}=5.7, M_{\mathrm{W}}=5.9\right)$. This sequence motivated the organization of a post-seismic survey of the SINAPS@ project (Hollender et al. 2015; Perron et al. 2017). This survey involved many instruments (i.e., accelerometers, broadband seismometers, rotation sensors) that were deployed on different soil conditions. All datasets recorded during the SINAPS@ post-seismic survey are open (Perron et al. 2017, see "Availability of data and materials" section for more information). The analysis of the accelerometer and broadband seismometer data "alone" has already led to several published studies 
(Berge-Thierry et al. 2016; Imtiaz et al. 2017; Svay et al. 2017). In the present study, we focus on the analysis of the rotation data, with the combination of the translational data recorded in co-location with the rotation sensors.

\section{Building the Kefalonia rotational datasets}

All of the sensors used in the post-seismic survey recorded the ground motion in continuous mode with a $200-\mathrm{Hz}$ sampling frequency. To build the event datasets, the National Observatory of Athens seismicity catalog was used to extract time windows from the continuous records. The extracted events then underwent systematic visual examination. The arrival times of the $\mathrm{P}$ waves $\left(T_{\mathrm{P}}\right)$ and $\mathrm{S}$ waves $\left(T_{\mathrm{S}}\right)$ were also manually picked from the time series. Only the events that had a signal-to-noise ratio $>10$ on both the translational and rotational records were kept. Here, the signal-to-noise ratios were evaluated directly on the time series after application of a $1-10 \mathrm{~Hz}$ bandpass filter. This relatively narrow filter was only used for the event selection. For the rest of the study, the data were filtered using a broader $0.5-50 \mathrm{~Hz}$ bandpass filter. The signals were also corrected to account for their respective instrumental responses. Only one rotation sensor (Eentec R-1; connected to a Nanometrics Taurus digitizer) was available for the post-seismic array. This sensor was tested by Bernauer et al. (2012) and used by several authors (e.g., Liu et al. 2009; Yin et al. 2016; Zembaty et al. 2017). Details about its instrumental response correction can be found in Yin et al. (2016). It was placed successively at three different locations, which provided three recording phases.

Initially, the rotation sensor was collocated with a translational accelerometer (Güralp CMG5; linked to a Nanometrics Taurus digitizer), from February 6, 2014, to February 19, 2014 (i.e., for around 2 weeks), within the Koutavos park at a soft-soil location (see below for more information on the soil conditions). This period is defined as "phase 1." Within the available open dataset described in Perron et al. (2017), this rotation sensor location is called "ROSA." Using this procedure (as described above), 421 events were extracted. Unfortunately, the analysis of these data showed that one of the horizontal components of the translational accelerometer did not work correctly, which prevented true six-component analysis. Hence, in the present study, the data from phase 1 are only used for the analysis of the rotation records. Note that the rotation sensor was "virtually" placed here in the center of a dense array that had been installed previously in the framework of the NERA program (funded by the European Union), which allowed complete analysis of the ground-motion coherency and the wavefield composition (Imtiaz 2015). This array was no longer in place for the
SINAPS@ post-seismic survey, but the results of the rotation measurement could be analyzed using the results of the Imtiaz (2015) study.

In the second step, the rotation sensor was installed at a rock site, in the center of a dense array that consisted of 21 broadband translational seismometers (Güralp CMG6TD; with integrated digitizers), from February 19, 2014, to March 10, 2014 (i.e., for around 3 weeks). This period is defined as "phase 2." Within the available open dataset described in Perron et al. (2017), this rotation sensor location is called "RORA." Phase 2 allows the comparison between the rotation and translation data and also the comparison with the wavefield composition extracted from the dense array (Imtiaz et al. 2017). However, the strongest events cannot be analyzed for this phase as the seismometers were saturating for strong motion (i.e., above a velocity of around $2.5 \mathrm{~mm} / \mathrm{s}$ for CMG6TD sensors). After rejection of the saturated records, it was possible to extract 118 events for which both translation velocity and rotation velocity motions were available.

Finally, at the end of the dense array experiment, the rotation sensor was installed in co-location with a translation accelerometer, again in the Koutavos basin, $140 \mathrm{~m}$ from the first location of phase 1 , at the location for the future permanent vertical array; this was operated from March 11, 2014, to July 2, 2015 (i.e., for around 16 months). This period is defined as "phase 3." Within the available open dataset described in Perron et al. (2017), this rotation sensor location is called "ROAN." Here, it was possible to extract 805 events with both rotation and translation data. The "Argonet" permanent vertical array has been operational since July 11, 2015, and the rotation sensor was kept on the site. Here, 29 events from the best records of the permanent array (up to July 28 , 2016) were added to this dataset to complete the dataset with the strongest motions. Phase 3 allows the comparison between rotation and translation data without any upper limit in terms of strong motions, which allows analysis over a wider range of motion levels and event magnitudes.

The main features used to build these three rotational datasets are given in Table 1, compared to three other datasets from the literature. Altogether, almost 1400 well-recorded events were extracted. Phase 1 is only partly used here as the failure of the associated translational sensor prevents 6-DOF analysis. Phase 2 is limited in terms of magnitude and ground-motion levels due do the use of velocimeters that saturated for strong motions. Fortunately, the dataset obtained covered a sufficiently large range of ground-motion levels to be useful in the analysis of the effects of the soil conditions, as this was recorded on a rock site. For convenience and 
Table 1 Main characteristics of the datasets used in the present study (PGTA: peak ground translational acceleration)

\begin{tabular}{|c|c|c|c|c|c|c|}
\hline \multirow[t]{2}{*}{ Datasets } & \multicolumn{3}{|c|}{ Kefalonia Island site } & \multicolumn{3}{|l|}{ Literature data } \\
\hline & $\begin{array}{l}\text { Soft soil (phase 1) } \\
\text { (ROSA) }\end{array}$ & $\begin{array}{l}\text { Rock (phase 2) } \\
\text { (RORA) }\end{array}$ & $\begin{array}{l}\text { Soft soil (phase 3) } \\
\text { (ROAN) }\end{array}$ & $\begin{array}{l}\text { Ito, Japan (Takeo } \\
\text { 2009) }\end{array}$ & $\begin{array}{l}\text { HGSD station, } \\
\text { Taiwan (Liu et al. } \\
\text { 2009) }\end{array}$ & $\begin{array}{l}\text { Garner Valley } \\
\text { Downhole Array } \\
\text { (Yin et al. 2016) }\end{array}$ \\
\hline Number of events & 421 & 118 & 834 & 216 & 52 & 74 \\
\hline Dates & $\begin{array}{l}6 / 02 / 2014- \\
19 / 02 / 2014\end{array}$ & $\begin{array}{r}19 / 02 / 2014- \\
10 / 03 / 2014\end{array}$ & $\begin{array}{r}11 / 03 / 2014- \\
31 / 07 / 2016\end{array}$ & $\begin{array}{r}\text { 20/04/1998- } \\
30 / 04 / 1998\end{array}$ & $\begin{array}{l}\text { 8/05/2007- } \\
17 / 02 / 2008\end{array}$ & $\begin{array}{r}11 / 10 / 2008- \\
30 / 12 / 2014\end{array}$ \\
\hline $\begin{array}{l}\text { Site conditions } \\
\left(V_{530} ; \mathrm{m} / \mathrm{s}\right)\end{array}$ & 250 & 830 & 250 & Unknown & Unknown & 280 \\
\hline$\underset{\left(\mathrm{m} / \mathrm{s}^{2}\right)}{\operatorname{Maximum} \text { PGTA }}$ & - & 0.15 & 3.72 & 3.44 & 0.47 & 1.20 \\
\hline $\begin{array}{l}\text { Magnitude cor- } \\
\text { responding to } \\
\text { maximum PGTA }\end{array}$ & - & 3.9 & 5.0 & 5.0 & 5.8 & 5.4 \\
\hline $\begin{array}{l}\text { Maximum magni- } \\
\text { tude }\end{array}$ & 4.7 & 3.9 & 6.3 & 5.0 & 6.6 & 7.2 \\
\hline Slope: $b$ & - & 0.96 & 0.89 & 1.09 & 0.97 & 0.90 \\
\hline Intercept: $a$ & - & -2.86 & -3.05 & -2.90 & -2.92 & -2.99 \\
\hline Standard deviation & - & 0.15 & 0.14 & 0.11 & 0.12 & 0.26 \\
\hline
\end{tabular}

homogeneity, all of the translational velocity records were converted into translational acceleration for the present study. Phase 3 is a rich dataset, as it contains a wide range of events in terms of magnitude, epicentral distance, and ground-motion level. Figure 2 shows the maps of the recorded events. Figure $3 a-c$ shows the epicentral versus magnitude distributions of these three Kefalonia Island datasets, including color representation of the peak ground translational acceleration (PGTA). The datasets of phases 1 and 2 are strongly dominated by the aftershock sequence of these early 2014 Kefalonia earthquakes. The phase 3 dataset is the most complete, and it also includes the main shock and major aftershocks of the Lefkada earthquake that occurred on November 17, $2015\left(M_{\mathrm{L}}=6.0, M_{\mathrm{W}}=6.4\right.$, according to the National Observatory of Athens seismicity cata$\log )$. The largest motion in this dataset was recorded on November 8, 2014 $\left(M_{\mathrm{L}}=M_{\mathrm{W}}=5.0\right)$, which was the result of a local earthquake. This record led to maximum PGTA $=3.72 \mathrm{~m} / \mathrm{s}^{2}$ and PGRV $=6.23 \times 10^{-3} \mathrm{rad} / \mathrm{s}$.

As already mentioned, the previous works by Imtiaz (2015) and Imtiaz et al. (2017) provided valuable information concerning the wavefield characteristics. These works allowed determining the respective energy amount of Love and Rayleigh waves within the whole seismic field for both the soft-soil and rock sites. They also allowed investigating the respective amount of "direct arrival" surface-wave energy (surface waves with a back-azimuth propagation direction within a $\pm 20^{\circ}$ angle around the source back-azimuth) and of the "diffracted" surface-wave energy (surface waves coming from other directions).
These studies showed that on both the soft-soil and rock sites, more than $80 \%$ [mean over the $(1-20 \mathrm{~Hz})$ frequency range] of the surface-wave energy has a diffracted origin.

Figure 4 shows examples of the time series recorded with both translational and rotational sensors after the 0.5 to $50 \mathrm{~Hz}$ bandpass filtering. Figure $4 \mathrm{a}$ shows the best (i.e., strongest, non-saturated) event recorded on the rock site (phase $2 ; M_{\mathrm{L}}=3.9 ; R_{\text {hypo }}=15.9 \mathrm{~km}$ ). Figure 4b shows the best event recorded on the soft-soil site (phase $3 ; M_{\mathrm{L}}=5.0 ; R_{\text {hypo }}=20.2 \mathrm{~km}$ ). Here, the translational sensor was an accelerometer, and hence, there was no saturation.

Figure 5 shows the amplitude spectrum densities (ASDs) computed on the signals and on the noise, and the signal-to-noise ratios of the time series shown in Fig. 4 (without any bandpass filtering). Figure 5 illustrates that the rotation sensor used had a higher noise level in comparison with the translational sensors. For example, for the event shown in Fig. $5 \mathrm{a}\left(M_{\mathrm{L}}=3.9 ; R_{\text {hypo }}=15.9 \mathrm{~km}\right.$, which corresponds to peak PGTA $=0.15 \mathrm{~m} / \mathrm{s}^{2}$, which is relatively significant ground motion), the signal-to-noise ratio was $<10$ below $2 \mathrm{~Hz}$, where the translational signalto-noise ratio was two orders of magnitude higher.

\section{"Peak value" analysis of the datasets}

The PGTA is one of the simplest and most widely used parameters in earthquake engineering. It is defined as the maximum in the time domain of the absolute value of the translational acceleration of the three components. By analogy, the PGRV is also the first analyzed parameter in rotational seismology. The analysis of these datasets 


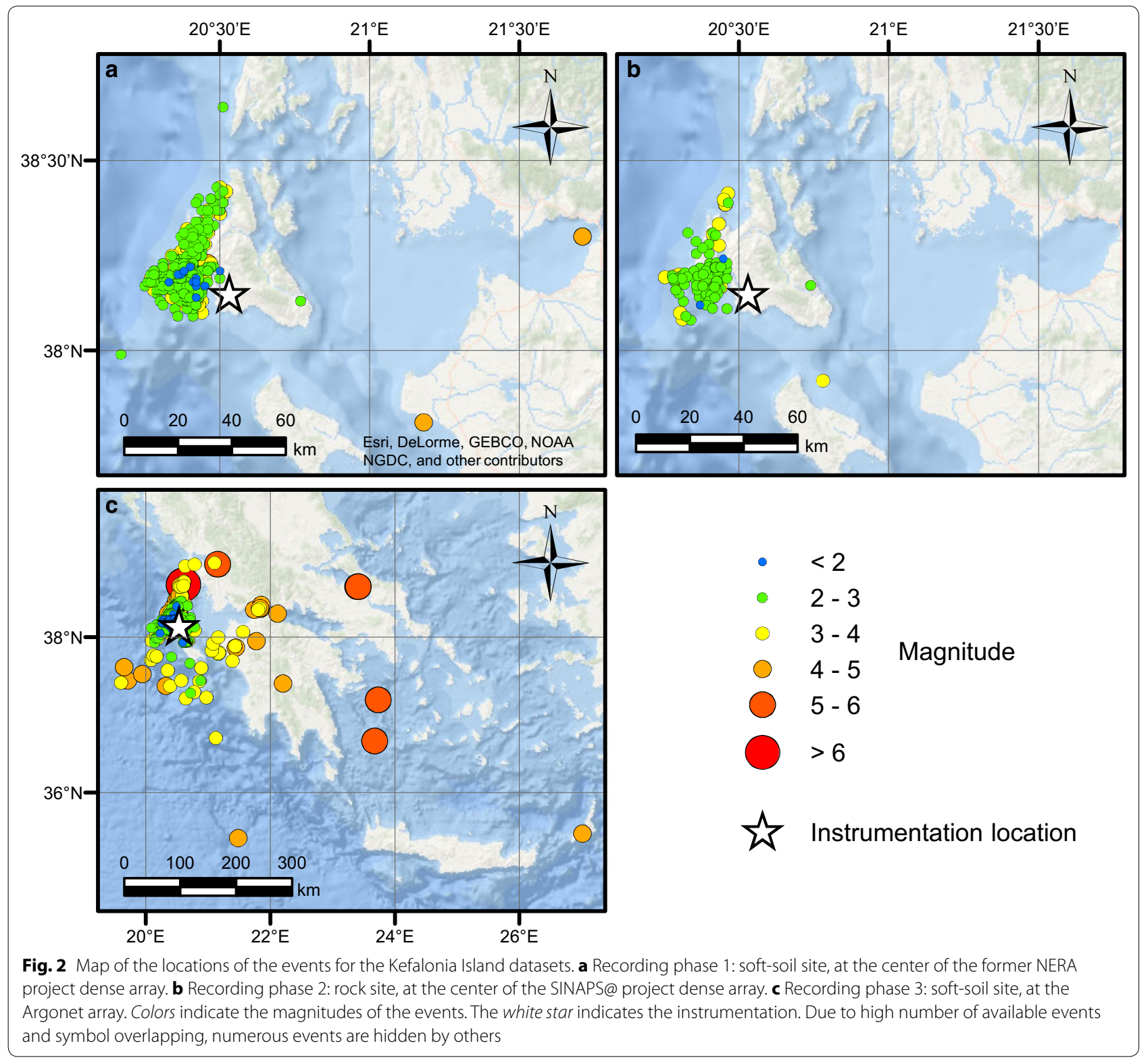

was initially carried out using these two parameters. Although comparing "acceleration" with "velocity" might appear inconsistent at first glance, those parameters are, however, those that are considered. Indeed, it is easy to show that under the assumption of transverse plane waves, the transverse translation acceleration $\ddot{u}_{y}(x, t)$ and rotation velocity $\Omega_{z}(x, t)$ are in phase at all times (e.g., Igel et al. 2005) and their ratio is linked to the propagation velocity $c$ :

$$
\frac{\ddot{u}_{y}(x, t)}{\Omega_{z}(x, t)}=-2 c .
$$

Figure 6 shows the PGRV as a function of the PGTA for the five datasets: the Kefalonia rock-site (phase 2) and soft-soil site (phase 3) datasets introduced here, and three other datasets from the literature (Liu et al. 2009; Takeo 2009; Yin et al. 2016). The magnitudes of the different events are shown according to a colour scale. The main features of these datasets are given in Table 1, and their magnitude/hypocentral distance distributions are illustrated in Fig. 3. The Liu et al. (2009) dataset was recorded at the HGSD station in Taiwan, which operated over almost 1 year. The Takeo (2009) dataset was obtained over a relatively short period, recording events from an earthquake swarm in April 1998 offshore of Ito (Japan). This is a very particular dataset since all events have almost the same hypocentral distance (Fig. 3e). Note that in the table provided in the paper of Takeo 

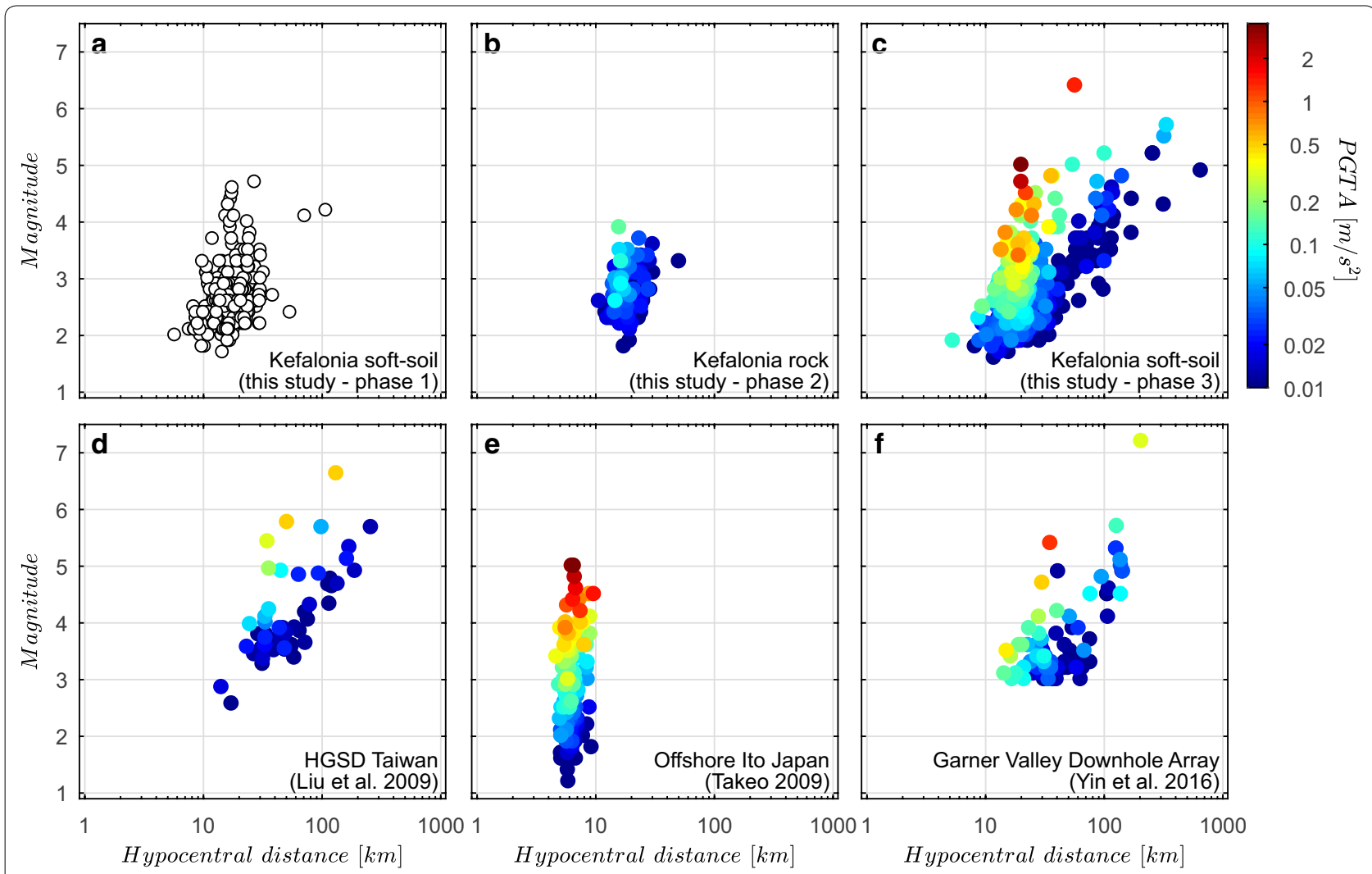

Fig. 3 Magnitudes, hypocentral distances, and peak ground translation acceleration (PGTA, see color scale on top light) of each recording of each dataset discussed in this paper (the Kefalonia Island datasets, as well as Liu et al. 2009; Takeo 2009; Yin et al. 2016 datasets). For the Kefalonia Island phase 1 dataset, no translational sensor data were available. a Kefalonia soft-soil recording phase 1 (NERA dense array location). b Kefalonia rock recording phase 2 (Sinaps@ dense array location).c Kefalonia soft-soil recording phase 3 (Argonet location).d HGSD station, Taiwan (Liu et al. 2009). e Ito, Japan (Takeo 2009). f Garner Valley Downhole Array (Yin et al. 2016)

(2009), we rejected three events that seemed outliers to us. The Yin et al. (2016) dataset was recorded at the GVDA (USA) over several years. The subsoil conditions are known through the $V_{\mathrm{S} 30}$ parameters for both of the Kefalonia datasets and the Yin et al. (2016) dataset.

Figure 7a shows the PGRV versus PGTA values for each event of each dataset, again using color to indicate the origin of the dataset. At first glance, all of the datasets show the same overall features, and the point clouds are more or less superimposed. To go further and perform a more quantitative comparison between these datasets, the linear regression between the logarithm $\left(\log _{10}\right)$ of the PGRV (expressed in $\mathrm{rad} / \mathrm{s}$ ) and the logarithm $\left(\log _{10}\right)$ of the PGTA (expressed in $\mathrm{m} / \mathrm{s}^{2}$ ) was computed according to the relationship shown in Eq. (2):

$$
\log _{10}(\text { PGRV })=a+b \log _{10}(\text { PGTA })
$$

The curves obtained are shown in Fig. $7 \mathrm{~b}$, and the $a$ and $b$ values from the regression and the standard deviation are given in Table 1 . To compute the regression with both of the Kefalonia datasets, only the data with PGTA $>5 \times 10^{-3} \mathrm{~m} / \mathrm{s}^{2}$ were considered, since the "real" point clouds were probably truncated below this value because of the applied signal-to-noise ratio criterion: keeping the whole dataset could have led to bias the regression.

All of the datasets are found to produce very similar regression lines, except the Takeo (2009) dataset, which has a greater slope. Lee et al. (2009b) already showed the difference in the slope between the Takeo (2009) and Liu et al. (2009) datasets. We suggest that this can be explained by an effect of the magnitude on the rotations. Indeed, Fig. 6d shows that there is a strong correlation between magnitude and PGTA (or PGRV), whereas, for the other datasets, the magnitudes are better "distributed" along the whole dataset distribution (see Fig. 3). The Takeo (2009) dataset is relatively different from the other ones as it recorded signals from a swarm at very short distances. However, this bias might also have an instrumental origin, as Takeo (2009) used an inertial angular displacement sensor, whereas all the 

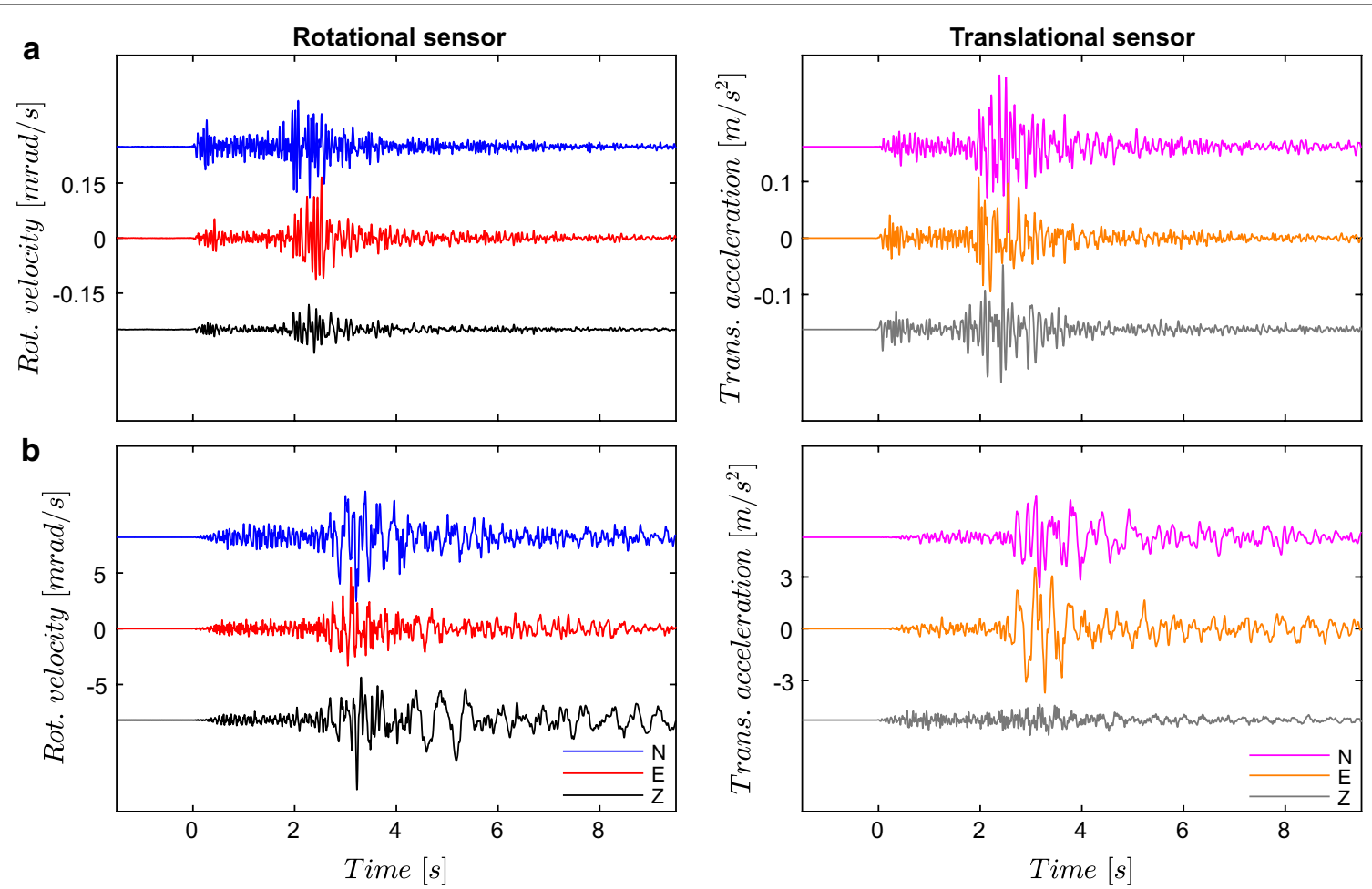

Fig. 4 Example time histories. a Records from the rock site $\left(M_{\mathrm{L}}=3.9 ; R_{\text {hypo }}=15.9 \mathrm{~km}\right)$. b Records from the soft-soil site $\left(M_{\mathrm{L}}=5.0 ; R_{\text {hypo }}=20.2 \mathrm{~km}\right)$. Left rotation sensor records. Right translational sensor records

other datasets (i.e., Kefalonia datasets; Liu et al. 2009; Yin et al. 2016) were recorded using electrochemical magnetohydrodynamic sensors. In terms of standard deviation, the datasets are also comparable, except for the Yin et al. (2016) dataset, for which the standard deviation is almost twice those of the other sites. It is also interesting to note that there is no a priori evidence of the impact of the soil conditions (i.e., differences between rock and soil sites) on the PGRV/PGTA relationship.

To go further, Fig. 8 distinguishes the rotational components by showing separately:

1. the peak torsion velocity (i.e., with torsion as the rotation around the vertical axis, which characterizes rotational movements in the horizontal plane) versus peak ground translational acceleration measured on the two horizontal components (denoted PGTA $_{H}$; Fig. 8a);

2. the peak rocking velocity (i.e., with rocking as the rotation around the horizontal axes) versus peak ground translational acceleration measured on vertical component (denoted PGTA $\mathrm{Z}_{\mathrm{Z}}$, Fig. 8b).

For the sake of simplicity, "torsion" and "rocking" will refer to "torsion velocity" and "rocking velocity" in the rest of this article. These comparisons were done on the two Kefalonia datasets and the Yin et al. (2016) dataset, as distinction between torsion and rocking was available. For the $\mathrm{PGTA}_{\mathrm{Z}} /$ rocking correlation, there are only slight differences between the datasets. For the $\mathrm{PGTA}_{\mathrm{H}} /$ torsion correlation, however, there is a clear difference between the datasets. Indeed, the Kefalonia rock-site dataset shows a significantly lower torsion for any given value of PGTA $_{H}$ than that seen for the other two datasets. The Yin et al. (2016) dataset also shows slightly lower torsion for a given PGTA $_{\mathrm{H}}$ than for the Kefalonia soft-soil dataset. Figure 9 shows the torsion velocity versus the rocking velocity. Here, again, there are differences between these three datasets. For all of these datasets, the rocking is statistically higher than the torsion, but the Kefalonia rock-site dataset shows the greatest differences between these (Fig. 9b). Figure 9a shows that for the Kefalonia rock-site dataset, all of the events show higher rocking than torsion. For the Yin et al. (2016) dataset, most of events have higher rocking than torsion, with only a few with higher torsion. For the Kefalonia soft-soil dataset, most of the events still have higher rocking than torsion (Fig. 9b, where the regression line remains beneath the 1:1 line on the torsion versus rocking plot), although quite a lot of the events have higher torsion than rocking. At the opposite end, Liu et al. (2009) observed that for the Liu et al. (2009) dataset of the HGSD station 


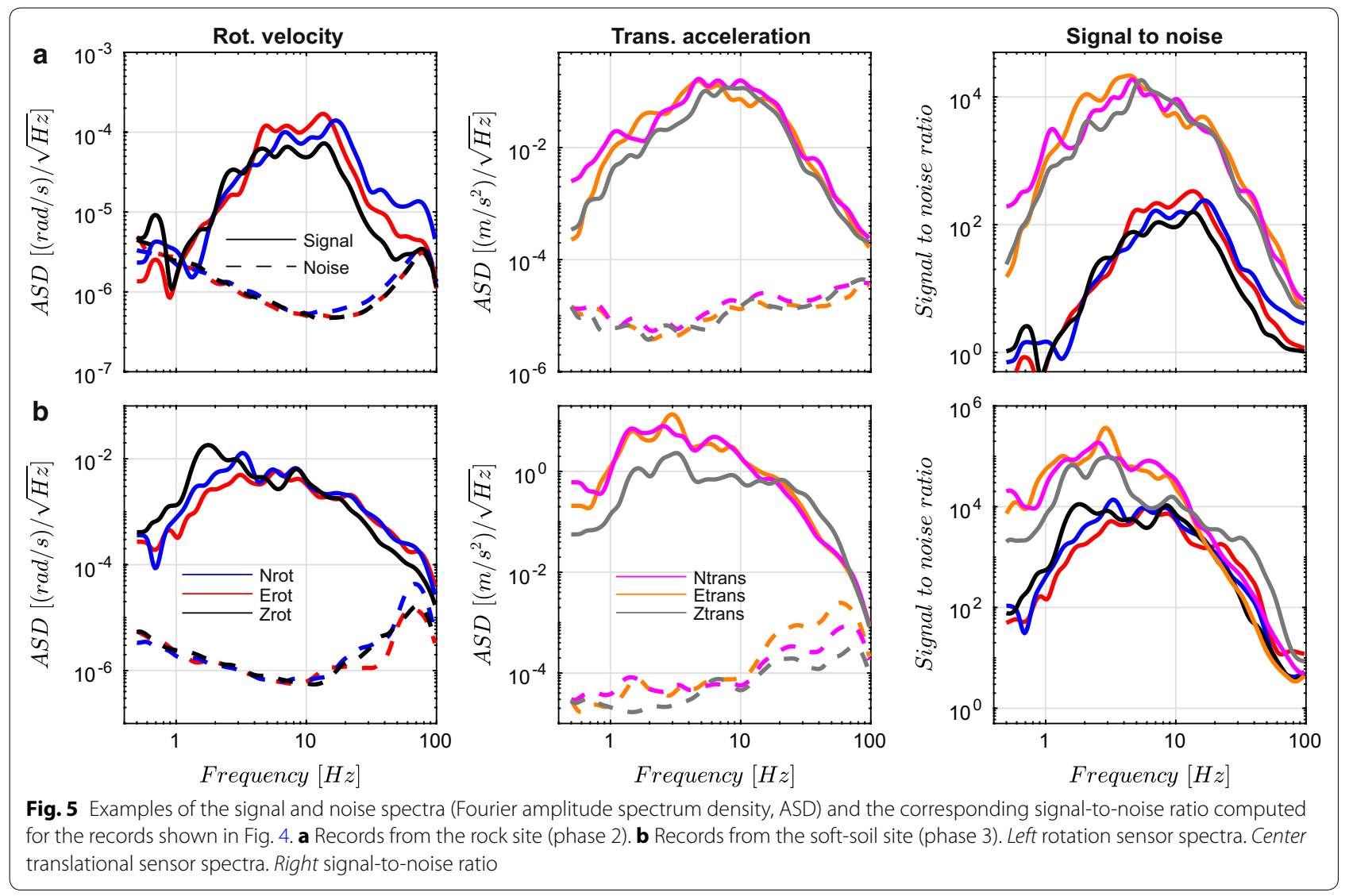

(Taiwan), the torsional components were mostly greater than the rocking components. Comparing the Yin et al. (2016) dataset with the Liu et al. (2009) dataset, Yin et al. (2016) indicated this difference between the rocking and torsion PGRV values and suggested that "the explanation for such difference may be attributed to the different site conditions and different source types in Taiwan and California."

The features observed in Figs. 8 and 9 suggest that, for the torsion versus PGTA and the torsion versus rocking correlations, the differences between these three datasets can be explained by local soil properties. Indeed, the dataset associated with the stiffer soil condition (i.e., the Kefalonia rock site; $V_{\mathrm{S} 30} \sim 830 \mathrm{~m} / \mathrm{s}$ ) showed the lowest torsion with respect to rocking and PGTA, whereas the datasets associated with the softer soil conditions (Kefalonia soft-soil site, Yin et al. 2016; $V_{\mathrm{S} 30} \sim 250,280 \mathrm{~m} / \mathrm{s}$, respectively) showed the highest torsion. In a more quantitative way, this confirms the suggestion of Yin et al. (2016) concerning the site condition effects (at the local scale) on the relative influence of torsion and rocking on the PGRV. These local conditions appear to actually have an effect on the maximum torsion, whereas no significant effects appeared to affect the maximum rocking.
Figure 10 shows the residuals (i.e., differences between each point and the regression curve) of previous regressions as a function of the magnitude in order to investigate whether this parameter affects the rotation/ translational acceleration relationship. For each dataset, the residuals were computed using the regression result of the corresponding dataset. In order to help in reading the trend of point clouds (in gray in Fig. 10), the different events were gathered in ten magnitude bins of equal size (i.e., same number of points), for each of which the mean and standard deviations are plotted in color in Fig. 10. For the three datasets where rotation components can be distinguished (Kefalonia rock and soft-soil, GVDA), the residuals were computed for whole rotation (Fig. 10a-c), rocking (Fig. 10d-f), and torsion (Fig. $10 \mathrm{~g}-\mathrm{i}$ ). For the Liu et al. (2009) and Takeo (2009) datasets, only the residuals on whole rotation are given (Fig. 10j, k).

The only clear magnitude effect is found for the GVDA (Yin et al. 2016) dataset, with a clear negative correlation (the higher the magnitude, the lower the rotation-for a given translational acceleration). This feature is observed on the whole rotation, rocking, and torsion (Fig. 10c, f, i). For the Kefalonia soft-soil dataset, and considering the level of standard deviation bars, a slight positive 

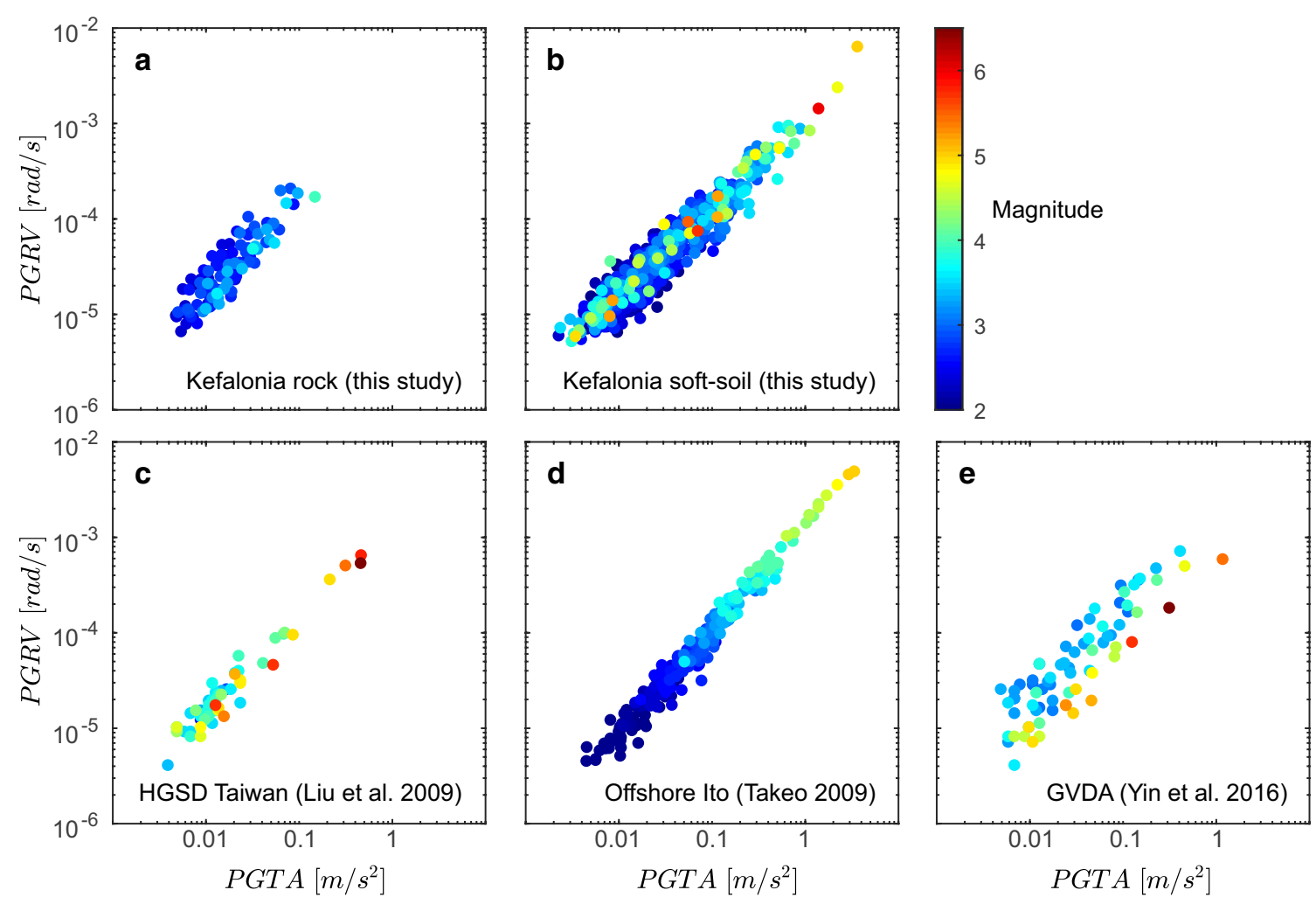

Fig. 6 Peak ground translation acceleration (PGTA; computed for all three components) versus peak ground rotation velocity (PGRV; computed for all three components) correlations for the two sites of the present study and from three other datasets from the literature. The magnitude of each event is given with the colour scale. a Kefalonia rock (this study). b Kefalonia soft-soil (this study). c HGSD Taiwan (Liu et al. 2009). d Offshore Ito (Takeo 2009). e GVDA (Yin et al. 2016)
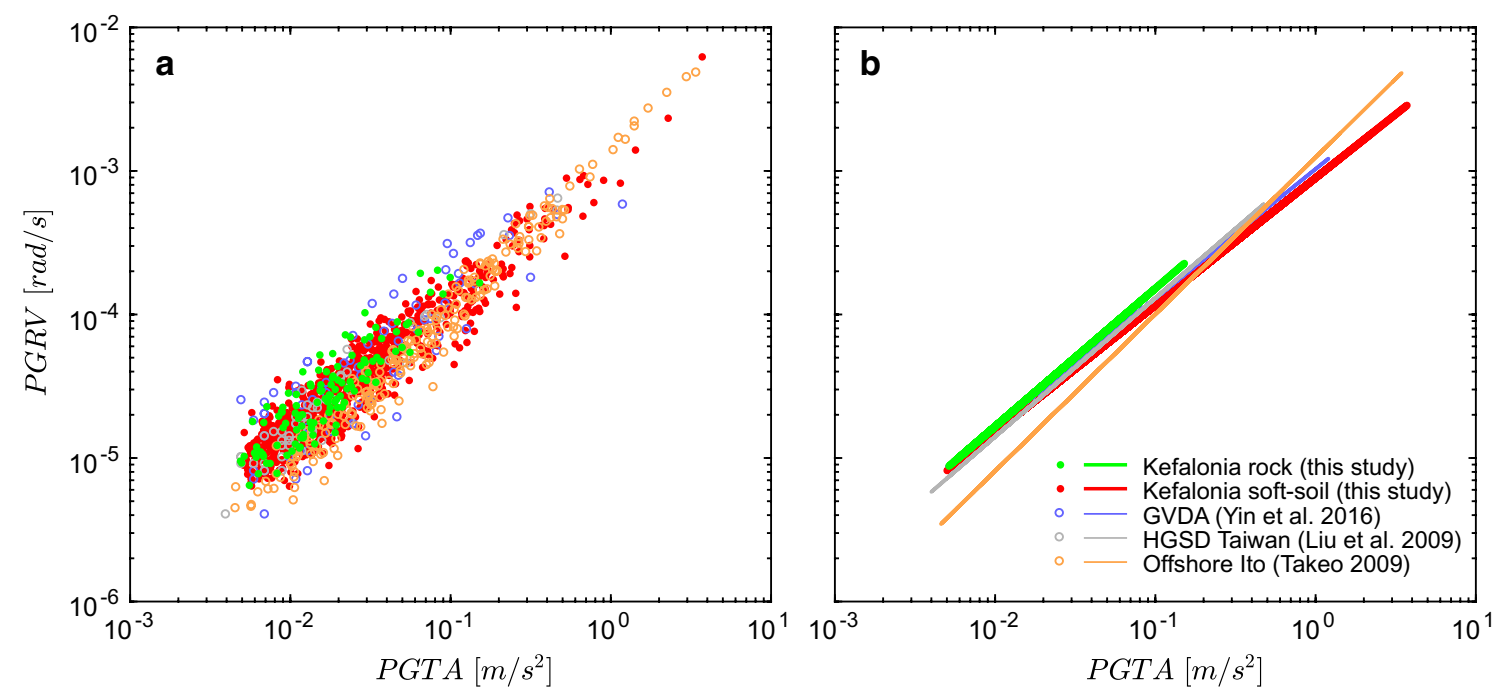

Fig. 7 Peak ground translation acceleration (PGTA) versus peak ground rotation velocity (PGRV) correlations for the two sites of the present study and from the three datasets from the literature. a All events. b Regression lines 

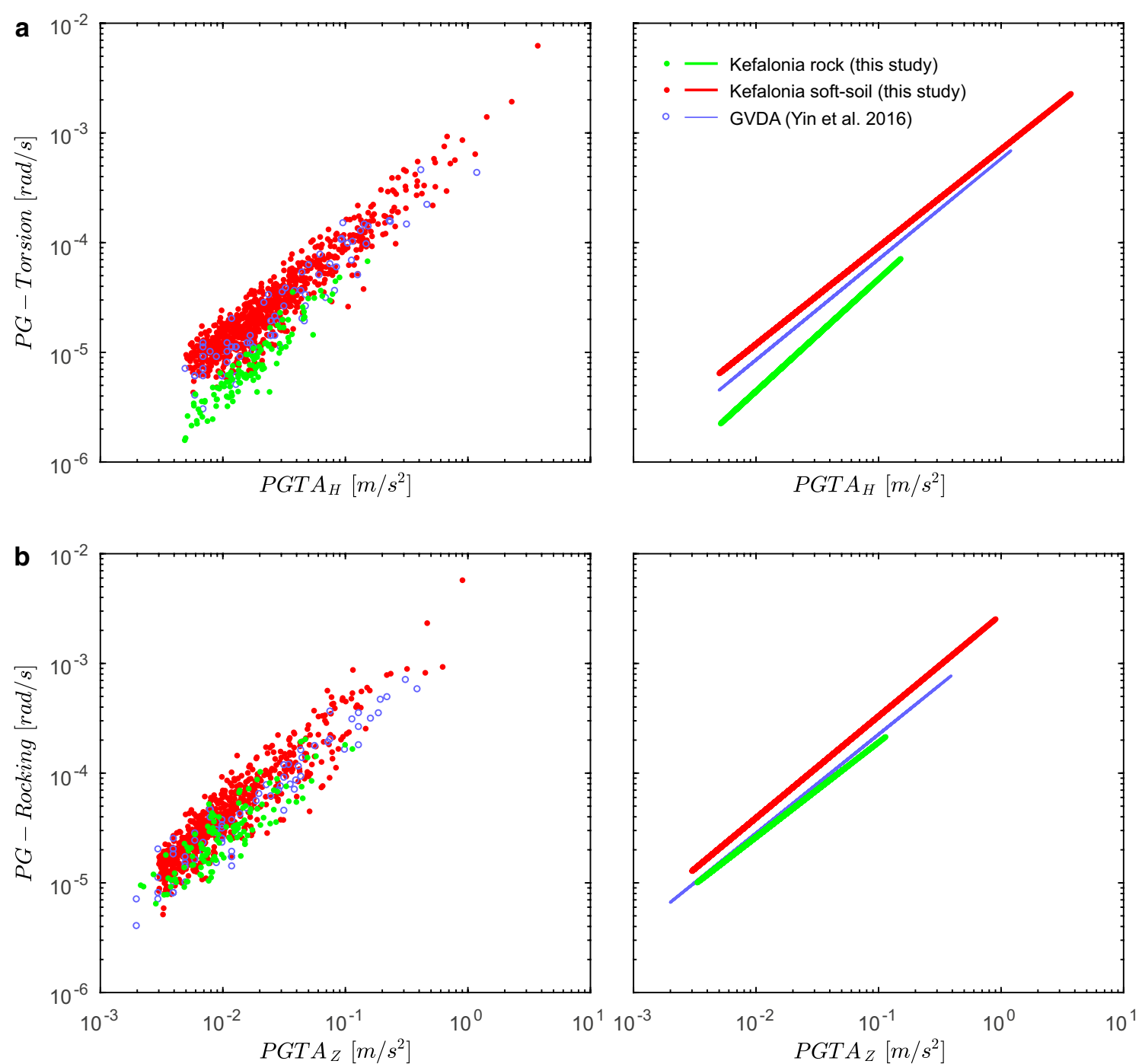

Fig. 8 Correlation between rotation velocity and peak ground translational acceleration (PGTA), with a differentiation between torsion/PGTA $(\mathbf{a}$, top) and rocking/PGTA $(\mathbf{b}$, bottom) for the two sites of the present study and for the Yin et al. (2016) GVDA site. Left all events. Right regression lines

correlation may be suggested for torsion only (Fig. 10h). No clear correlation arises from other datasets. The magnitude range of the Kefalonia rock dataset is anyway probably too reduced to exhibit a trend. Note, however, that for the particular distribution of the Takeo (2009) dataset in terms of magnitude, distance, PGRV, and PGTA (see Fig. 6d) no correlation can be found between magnitude and residuals (torsion Fig. 10i). If we compute the residuals of the Takeo (2009) using a regression line common to the whole datasets points, then a positive correlation between magnitude and residuals (the higher the magnitude, the higher the rotation-for a given translational motion) appears very clearly (it is not shown here, but can be inferred from the larger slope value of the regression line for this particular data, see Table 1).
Other residuals tests were performed for back-azimuth, hypocentral distance, and signal duration (depending on available information on the different datasets). For backazimuth, no trends were found. For hypocentral distance and signal duration, the (slight) possible trends were likely affected by a trade-off from magnitude (large magnitude being generally associated with larger hypocentral distance and larger signal duration).

These analyses were done on peak values, and we did not differentiate horizontal components according to the source back-azimuth in terms of transverse and radial components. Neither have we done any analysis on the possible effect of source rupture orientation, although this effect could have a potential impact the on rotational wavefield, as shown by Bernauer et al. (2014). 

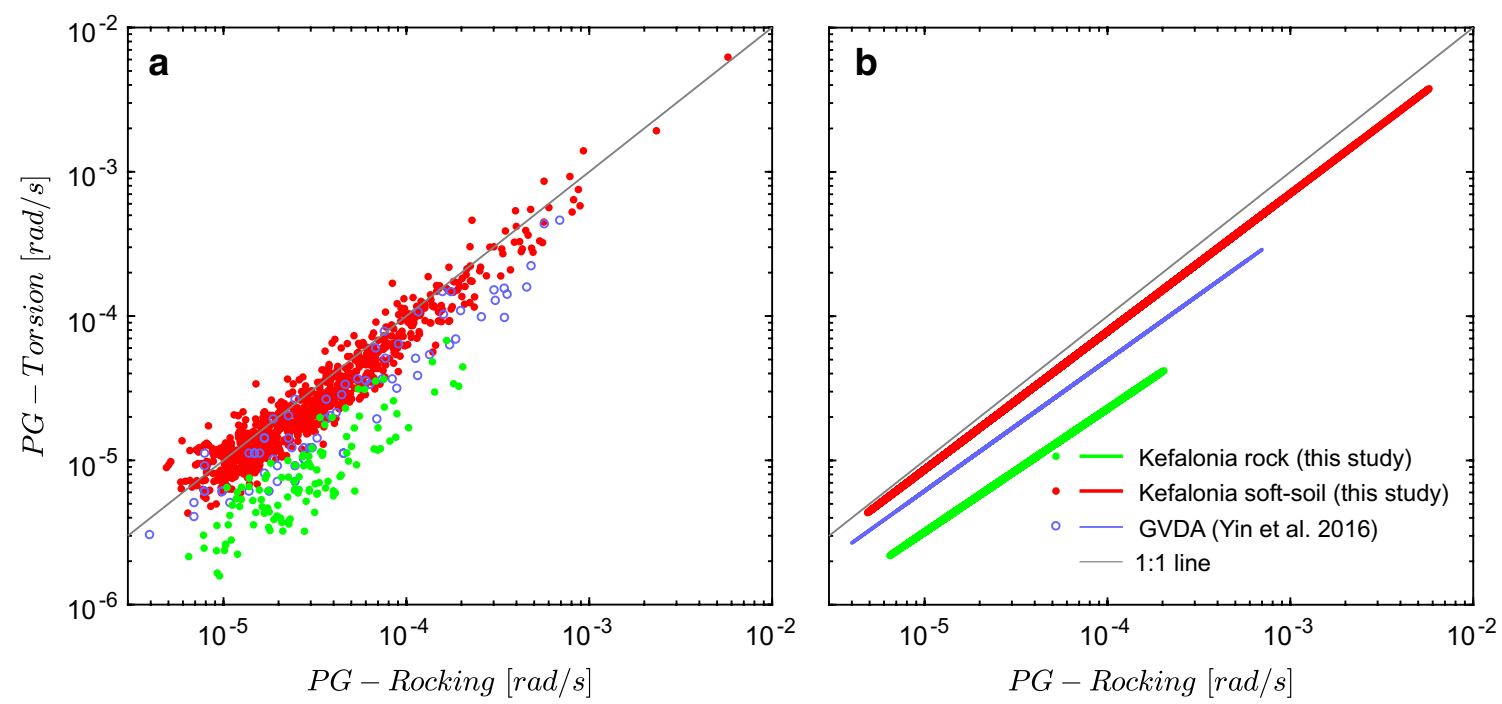

Fig. 9 Correlations between rocking and torsion for the two sites of the present study and from Yin et al. (2016). a all events. b regression lines

Such analyses may be performed in the future on the datasets used in this paper, which are open (Perron et al. 2017). However, as shown by Imtiaz (2015) and Imtiaz et al. (2017), the surface waves contained within the whole wavefield are largely dominated by diffracted surface waves that are independent of source back-azimuth of rupture orientation. So, we do not think that such effect can be observable on the rotational wavefield, at least within the frequency range of analysis [roughly $(1-20 \mathrm{~Hz})]$. The future use of spatial derivative using the velocimeter dense array deployed on the rock site could, however, potentially allow performing such kind of analysis at a frequency lower than the one than the one measured by the rotation sensor.

\section{Spectral analysis of the datasets}

Analyses of the "peak ground motion" values are often not sufficient in earthquake engineering, as they do not address the frequency content of the ground motion. To go further, frequency analyses of the translation acceleration/rotational velocity and rocking/torsion relationships were performed on the Kefalonia datasets. The ASDs were used. For the different spectral ratios shown here (Figs. 11, 12), the following procedures were used. First, the ASDs were computed for all of the components of all of the sensors for each event. These ASDs were then smoothed using the Konno and Ohmachi (1998) smoothing approach (with a $b$ parameter of 40). For each ASD, only the frequency ranges where the signal-to-noise ratio was $>10$ were kept. The different ratios were computed for each recorded event. Then, the means and standard deviations were computed using all of these former "single event" ratios, and assuming a lognormal distribution.
Finally, for the final mean and standard deviation curves, only the frequency ranges where at least ten events were available to compute the mean were kept. The following notations are used here:

- $E_{\text {rot }}$ ASD of the rotational velocity around the eastwest axis;

- $N_{\text {rot }}$ ASD of the rotational velocity around the north-south axis;

- $Z_{\text {rot }}$ ASD of the rotational velocity around the vertical;

- $E_{\text {trans }}$ ASD of the translational acceleration along the east-west axis;

- $N_{\text {trans }}$ ASD of the translational acceleration along the north-south axis;

- $Z_{\text {trans }}$ ASD of the translational acceleration along the vertical.

To combine horizontal components, the following Eqs. (3) and (4) were used:

$$
\begin{aligned}
& H_{\text {rot }}=\sqrt{\frac{E_{\text {rot }}^{2}+N_{\text {rot }}^{2}}{2},} \\
& H_{\text {trans }}=\sqrt{\frac{E_{\text {trans }}^{2}+N_{\text {trans }}^{2}}{2} .}
\end{aligned}
$$

The use of a factor of 2 at the denominator here is just the convention that allows the result to be 1 for the vertical-to-horizontal ratios when all three components carry the same energy. 


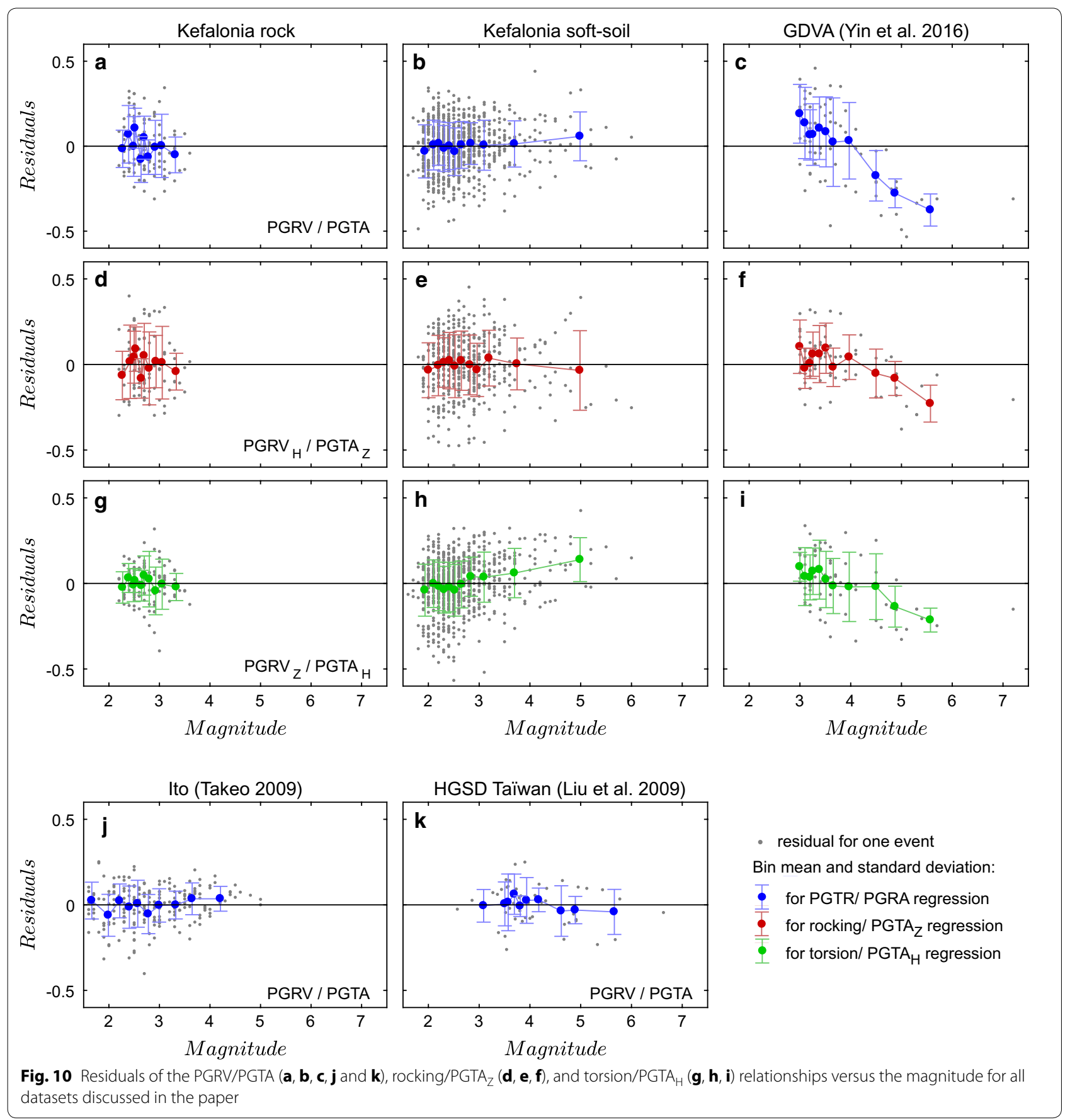

As the rotation around the vertical axis (i.e., torsion) corresponds to motion in the horizontal plane, $Z_{\text {rot }}$ has to be compared to $H_{\text {trans. }}$. Conversely, the rotation around the horizontal axes, $H_{\text {rot }}$, has to be compared to $Z_{\text {trans. }}$. Both $Z_{\text {rot }} / H_{\text {trans }}$ and $H_{\text {rot }} / Z_{\text {trans }}$ are shown as functions of the frequency in Fig. 11, for both the Kefalonia rock-site and soft-soil datasets. The ratios related to the Kefalonia rock-site dataset are relatively limited in the low frequency because of the saturation of the seismometers used for the translational motion measurements, which discarded large-magnitude events, i.e., those which have the largest low frequency content.

Overall, the relationships between translational acceleration and rotational velocity are particularly complex and highly frequency dependent. The ratio between torsion velocity and horizontal acceleration is lower for the rock 

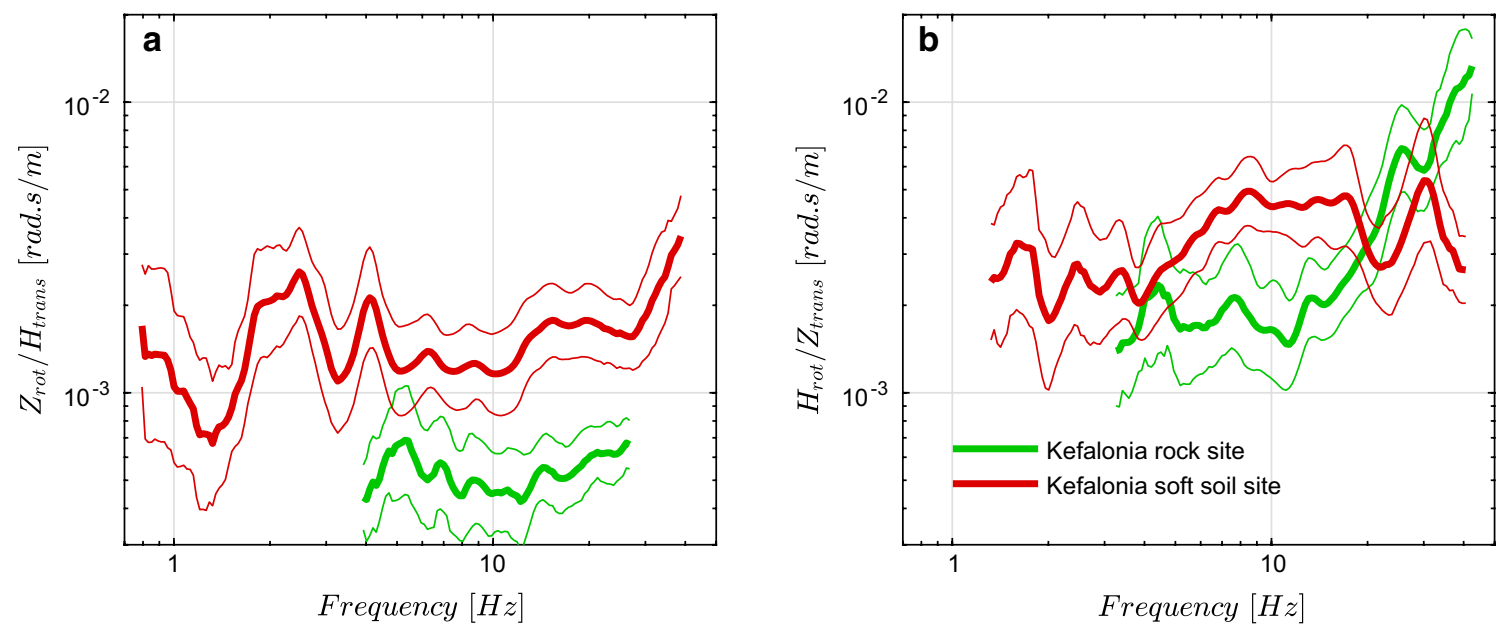

Fig. 11 a Ratio of the torsional component amplitude spectrum density (ASD) $\left(Z_{\text {rot }}\right)$ to the horizontal translational acceleration ASD $\left(H_{\text {trans }}\right)$ for the soft-soil (red) and rock (green) sites. b Ratio of the rocking component ASD ( $\left.H_{\text {rot }}\right)$ to the vertical translational acceleration component ASD ( $\left.Z_{\text {trans }}\right)$. In each case, the thick central line is the average ratio from many events with $S / N$ ratio beyond 10 , while the thin lines correspond to the average \pm one standard deviation

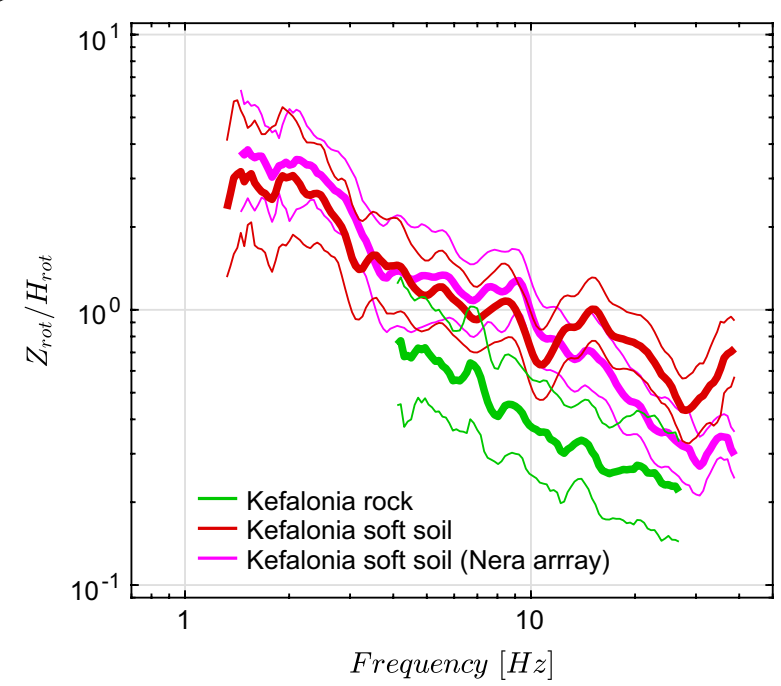

Fig. 12 Ratios of the torsional component amplitude spectrum density (ASD) $\left(Z_{\text {rot }}\right)$ to the rocking component ASD $\left(H_{\text {rot }}\right)$ for the soft-soil and rock sites

site than for the soft-soil site over the whole range of analyzed frequencies, which is consistent with previous observations using "peak ground value" analysis. For the rocking velocity to the vertical translation acceleration ratio, the rock site is higher than the soft-soil site at very high frequencies $(>20 \mathrm{~Hz})$ and lower between 4 and $20 \mathrm{~Hz}$. These features show that the "peak ground value" analysis is not sufficient to describe the wavefield complexity.

Figure 12 shows the $Z_{\text {rot }} / H_{\text {rot }}$ ratio, i.e., the torsionto-rocking ratio. Figure 12 was built using only the rotation velocity sensor data, so that the phase 1 Kefalonia soft-soil dataset can be represented and compared with the two other phases. The two soft-soil datasets show relatively close results, with a steady decrease with increasing frequency. For the soft-soil site, roughly, the torsion is dominant below $10 \mathrm{~Hz}$, whereas the rocking is dominant above $10 \mathrm{~Hz}$. Within the frequency band where it is available, the rock dataset $Z_{\text {rot }} / H_{\text {rot }}$ ratio shows a similar decrease with increasing frequency, and the rocking is dominant at all frequencies (beyond $4 \mathrm{~Hz}$ ). That the rock ratio is below the soft-soil ratios is consistent with previous data, where it was shown that the torsion of a rock site is lower than that of a soft-soil site. However, the frequency dependence of the torsionto-rocking ratio also illustrates that the "peak ground value" analysis is not sufficient to describe the wavefield complexity.

\section{Discussion: links to the surface-wave content}

Within a one-dimensional layered medium, and for a sufficiently distant earthquake (i.e., assuming that the incident body waves are nearly vertical), rotation is dominated by surface waves. The predominance of surface waves may be enhanced in soft sites such as the Koutavos park because of the trapping of surface waves generated on the nearby valley edges. Following the equations given in Marano and Fah (2014), the rotations $\omega_{x}, \omega_{y}$, and $\omega_{z}$ (around the $x, y$, and $z$ axes, respectively) due to the Love wave can be described by Eq. (5):

$$
\begin{aligned}
& \omega_{x}(p, t)=0 \\
& \omega_{y}(p, t)=0 \\
& \omega_{z}(p, t)=\frac{1}{2} \alpha_{\mathrm{L}} \kappa \sin \left(\omega t-\kappa \cdot p+\varphi_{\mathrm{L}}\right),
\end{aligned}
$$


where $p$ is the position (at the surface), $t$ is the time, $\omega$ is the temporal angular frequency, $\kappa$ is the wave vector, and $\alpha_{\mathrm{L}}$ and $\varphi_{\mathrm{L}}$ are the amplitude and phase of the Love wave, respectively. The Love wave thus produces pure torsion rotation.

The rotation due to the Rayleigh wave can be described by Eq. (6):

$$
\begin{aligned}
& \omega_{x}(p, t)=\alpha_{\mathrm{R}} \kappa \sin \psi \cos \xi \cos \left(\omega t-\kappa \cdot p+\varphi_{\mathrm{R}}\right) \\
& \omega_{y}(p, t)=-\alpha_{\mathrm{R}} \kappa \cos \psi \cos \xi \cos \left(\omega t-\kappa \cdot p+\varphi_{\mathrm{R}}\right) \\
& \omega_{z}(p, t)=0
\end{aligned}
$$

where $\psi$ is the wave propagation direction, $\xi$ is the ellipticity angle (with $|\tan \xi|$ as the ellipticity), and $\alpha_{\mathrm{R}}$ and $\varphi_{\mathrm{R}}$ are the amplitude and phase of the Rayleigh wave. The Rayleigh wave thus produces pure rocking rotation. When $\xi= \pm \pi / 2$, the polarization is horizontal, and in this case, the Rayleigh wave does not produce any rotation. This is, for example, the case at the fundamental frequency $\left(f_{0}\right)$ of a site that is constituted by a homogeneous layer overlying a half-space.

The spectral ratios shown in Fig. 11 could be used to evaluate if 6-DOF measurements may measure the phase propagation velocity as suggested in Eq. (1). Figure 13 displays the same results in terms of phase velocity from the ratio between translation acceleration in horizontal plane and torsion. Based on previous equations, this ratio should actually be controlled by the contribution of Love waves. Hence, in Fig. 13, the "theoretical" phase velocity of the fundamental mode of the Love wave is also drawn, using the velocity profiles available from former geophysical surveys (cross-hole and down-hole measurements performed on the soft-soil site, as well as surface-wave-based methods performed on both the rock and soft-soil sites, Hollender et al. 2015; Imtiaz et al. 2017; Svay et al. 2017). The Love phase velocities computed using 6-DOF measurements and the one computed using the velocity profiles are comparable, with an overestimation by 6 -DOF measurements at high frequency and an underestimation at lower frequency. However, the possible existence of higher modes within the whole wavefield, even with rather low amplitudes, might bias the estimate of phase velocities from amplitude ratios (Kurrle et al. 2010). The same computation was done using rocking and vertical translation acceleration compared to Rayleigh-wave phase velocity. However, in this case, the results were much worse, with a large underestimation of phase velocity by 6-DOF measurements.

The ratio between the torsion and the rocking (as shown in Fig. 12) can also be related to the Love-to-Rayleigh energy ratio, according to Eqs. (7)-(9):

$$
Z_{\text {rot }}=\omega_{z}=\alpha_{\mathrm{L}} \kappa_{\mathrm{L}} / 2,
$$

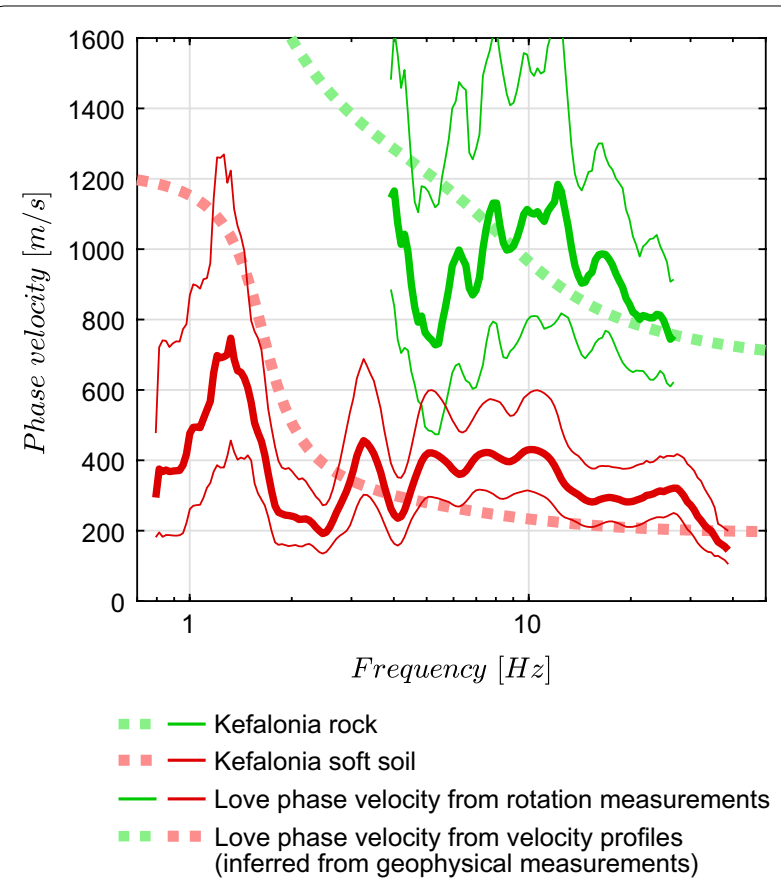

Fig. 13 Comparison of Love-wave phase velocity estimated using rotation sensor data [cf. Eq. (1)] and inferred from shear-wave velocity profiles (based on geophysical measurements) on both Kefalonia soft-soil and rock sites

$$
H_{\mathrm{rot}}=\sqrt{\left(\omega_{x}^{2}+\omega_{y}^{2}\right) / 2}=\alpha_{\mathrm{R}} \kappa_{\mathrm{R}} \cos (\xi) / \sqrt{2},
$$

so that:

$$
\frac{E_{\mathrm{L}}}{E_{\mathrm{R}}}=\left(\frac{\alpha_{\mathrm{L}}}{\alpha_{\mathrm{R}}}\right)^{2}=2\left(\frac{Z_{\mathrm{rot}}}{H_{\text {rot }}}\right)^{2}\left(\frac{1}{1+\tan ^{2}(\xi)}\right)\left(\frac{\nu_{\mathrm{L}}}{\nu_{\mathrm{R}}}\right)^{2}(9)
$$

where $E_{\mathrm{L}}$ and $E_{\mathrm{R}}$ are the energies of the Love and Rayleigh waves, respectively, and $v_{\mathrm{L}}$ and $v_{\mathrm{R}}$ are the velocities of the Love and Rayleigh waves, respectively.

Assuming the Rayleigh ellipticity is a fraction $\varepsilon$ of the horizontal to vertical spectral ratio (HVSR) measured from ambient vibration recordings (Nogoshi and Igarashi 1971; Nakamura 1989; Bard 2008), this equation can then be written as:

$$
\frac{E_{\mathrm{L}}}{E_{\mathrm{R}}}=2\left(\frac{Z_{\mathrm{rot}}}{H_{\mathrm{rot}}}\right)^{2}\left(\frac{1}{1+\varepsilon^{2} \mathrm{HVSR}^{2}}\right)\left(\frac{\nu_{\mathrm{L}}}{\nu_{\mathrm{R}}}\right)^{2} .
$$

Ambient vibrations measurements are available on the Kefalonia rock and soft-soil sites, and this ratio can thus be bounded with the two extreme assumptions $\varepsilon=0$ and $\varepsilon=1$.

The surface-wave energy ratios can also be determined through analysis of the wavefield composition 
analysis (i.e., the respective parts of the body, Love, and Rayleigh waves within the whole seismic motion) using dense arrays of translational sensors. This can be done using, for example, the MUSIQUE algorithm (Hobiger et al. 2012). This kind of analysis was performed for the Kefalonia soft-soil site by Imtiaz (2015) using a 21-sensor dense array that was deployed from September 20, 2011, to April 17, 2012, within the framework of the NERA European research program. For the first phase of the recording, the rotation sensor of the SINAPS@ postseismic experiment was located at the exact position of the center of this former array. A similarly dense, 21-sensor array was also deployed on the Kefalonia rock site, simultaneously with the recording of the rotational data. The wavefield compositions were then also analyzed by Imtiaz et al. (2017). The results of these analyses on these dense arrays of both of the sites are given in Fig. 14a, in terms of the percentages of the energies of the Love and Rayleigh waves within the whole seismic motion wavefield energy. The total energy of the surface wave is clearly higher on the soft-soil site. However, it can be seen that this difference is mainly caused by a difference in Lovewave content. Globally, this Rayleigh-wave content is just a little higher on the soft-soil site. Assuming that the torsion is dominated by the Love waves and the rocking is dominated by the Rayleigh waves, this is consistent with previous observations for the PGTA/rocking and PGTA/ torsion correlations (see Fig. 8).

To compare the data obtained by the rotation measurement with those obtained by dense array analysis in terms of the energy ratio between the Love and Rayleigh waves (here, we use the energy ratio of the diffracted surface waves which are largely dominant within the whole wavefield), Eq. (10) was applied to the $Z_{\text {rot }} / H_{\text {rot }}$ ratios of both of the sites, considering, to the first order, $v_{\mathrm{L}}=v_{\mathrm{R}}$. This approximated relationship needed to use the results of HVSR, as shown in Fig. 14b. The final results and comparisons are shown in Fig. 14c, which shows the $E_{\mathrm{L}} / E_{\mathrm{R}}$ ratio that was derived from the array measurements, the $E_{\mathrm{L}} / E_{\mathrm{R}}$ ratio that was derived from the rotational measurements without ellipticity correction [i.e., assuming $\varepsilon=0$ in Eq. (10)], and the $E_{\mathrm{L}} / E_{\mathrm{R}}$ ratio that was derived from the rotational measurements with the maximum ellipticity correction [i.e., assuming $\varepsilon=1$ in Eq. (10)].

Overall, and for both sites, the comparisons between the curves inferred from the rotation sensor data and the curves inferred from the array analysis are particularly satisfactory. For the rock site, the correspondence between the array measurements and rotation measurements with ellipticity correction is very satisfactory between 4 and $10 \mathrm{~Hz}$. However, above this frequency, rotation measurements produced higher $E_{\mathrm{L}} / E_{\mathrm{R}}$ values. This difference might be due to the very low amount of
Love-wave energy $(<2 \%)$ derived from the array analysis (Fig. 13a, left, pink curve); this level is probably below the capability of the array analysis. We believe that rotation measurements are more reliable to determine $E_{\mathrm{L}} / E_{\mathrm{R}}$ in this case and in this frequency range.

On the soft-soil site, the HVSR curve shows a significant and clear peak centered at $1.57 \mathrm{~Hz}$. The ellipticity correction here is significant, especially at frequencies below $4 \mathrm{~Hz}$. Above this frequency, and up to $20 \mathrm{~Hz}$, the correspondence between the array measurements and rotation measurements with ellipticity correction is very satisfactory. Below $4 \mathrm{~Hz}$, the curve derived from the rotation measurements without the ellipticity correction $(\varepsilon=0)$ overvalues the curve derived from the array measurements, which in turn overvalues the curve obtained with the full ellipticity correction $(\varepsilon=1)$. Here, the assumption that HVSR is dominated by Rayleigh waves is probably not completely valid as suggested by the large proportion of Love waves below $3 \mathrm{~Hz}$ derived from array analysis (Fig. 14a), and a better consideration of ellipticity might optimize these results.

The equations mentioned above and the subsequent figures and discussions are valid in one-dimensional layered media. From a geomorphological point of view, this assumption is easily verified on the rock site where the geology consists in tabular cretaceous limestones. As for the soft-soil site, located within the Koutavos basin, the 1D hypothesis can be commented using the shape ratio $h / l$ notion (Bard and Bouchon 1985). For the Koutavos basin case, $h$ (the basin thickness) is around $80 \mathrm{~m}$ and $l$ (the half-width of the basin) is around $500 \mathrm{~m}$, which results in a shape ratio around 0.16 . In this configuration, the Koutavos basin is clearly within the "1D resonance" case associated with generation of surface waves at the basin sides, according to the terminology proposed by Bard and Bouchon (1985). Despite these diffractions generated on the basin sides, the 1D interpretation of surface waves remains locally valid and is governed by the local 1D velocity profiles (Bard and Bouchon 1980a, b). Indeed, the work by Imtiaz (2015) and Imtiaz et al. (2017) showed that, for the soft-soil site, the surface-wave wavefield content is dominated by diffracted waves, but most surprisingly, it also showed that this feature is also true for the rock site.

Pham et al. (2009), analyzing rotational motion within the P coda, discussed on the fact that no torsional motion can be observed within a homogeneous media and that the observed torsion may be due to scattering within the crust. Beyond the observation that the surface-wave content is dominated by diffracted waves on both studied sites within the $(1-20 \mathrm{~Hz})$ frequency band, we think that the higher amount of torsional motion on soft soil, that we interpret as a higher amount of Love waves, is mainly 


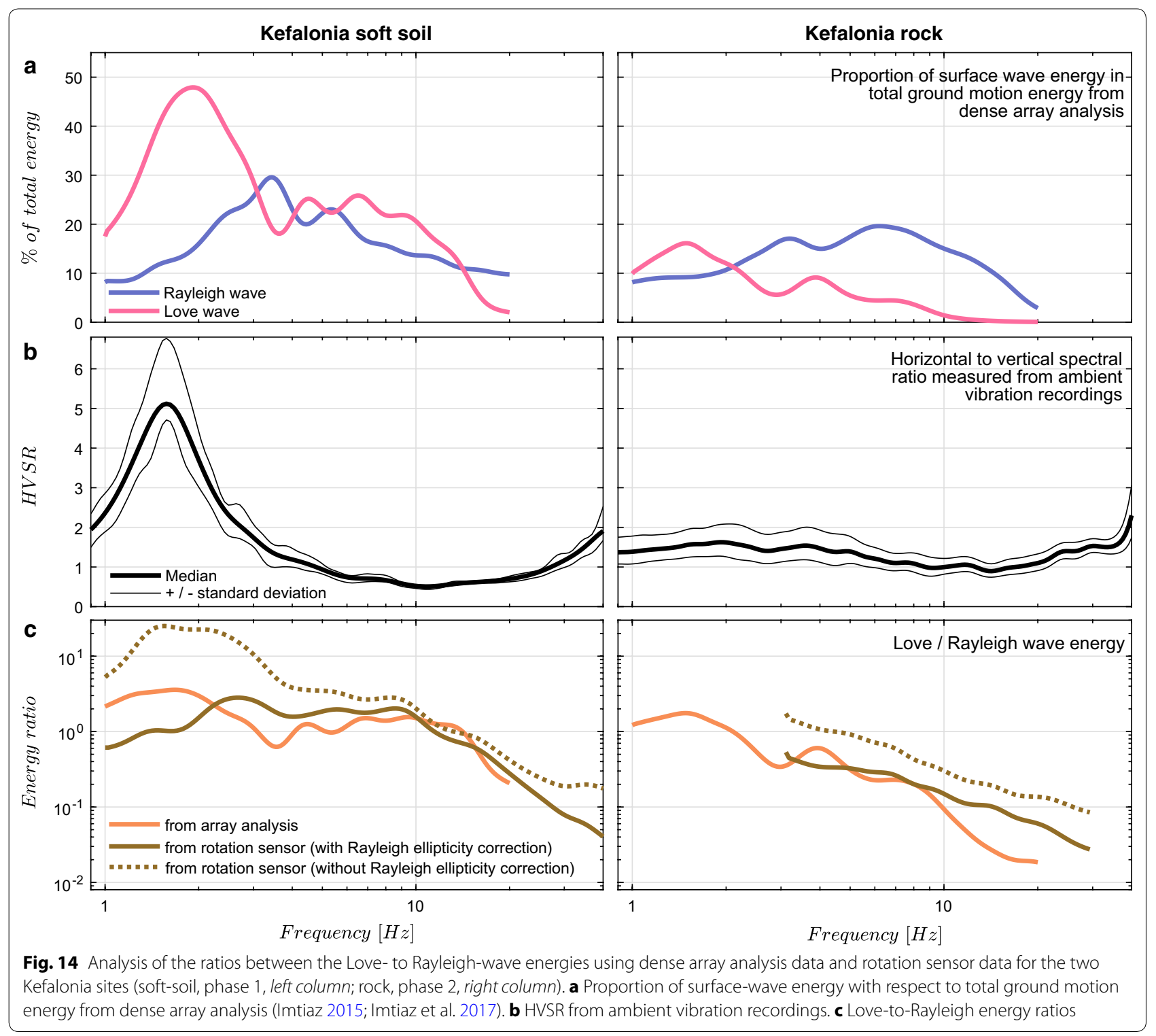

due to the lower S-wave velocity in near surface and the valley geometry. These surface low velocities are the corollary of an overall more pronounced velocity contrast with the deeper crust velocity that hence foster the formation of local Love waves on valley edges.

\section{Conclusions}

The post-seismic survey that was conducted on Kefalonia Island after the two large earthquakes $\left(M_{\mathrm{W}}=6.0\right.$, $M_{\mathrm{W}}=5.9$ ) that occurred on January 26, 2014, and on February 3, 2014, allowed to gather new comprehensive datasets combining translational and rotational measurements (6-DOF) on rock and soil sites with well-characterized site conditions. The analysis of these datasets and of three other datasets from the literature shows that there are no significant effects of the site conditions in terms of the relationships between translation and rotation analyzed according to PGTA (i.e., the peak time domain values of the absolute value of the translational acceleration of the three components) and PGRV (i.e., maximum in the time domain of the absolute value of the rotational velocity of the three components). However, when distinguishing torsion (i.e., rotation around the vertical axis, dominated by Love waves) and rocking (i.e., rotation around the horizontal axes, dominated by Rayleigh waves), the site conditions are found to affect the amount of torsional motion: the stiffer the soil, the lower the torsion for a given level of translational acceleration. 
In other words, rock sites show lower torsion during an earthquake in comparison with soft-soil sites. As far as rocking is concerned, the differences between these sites are much weaker.

The high number of events available for the Kefalonia soft-soil dataset (834) allowed determination of whether the magnitude, back-azimuth, hypocentral distance, and signal duration have any influence on the correlation of the peak of rotation, rocking, or torsion with PGTA. Only a small effect of the magnitude was suggested, and only for the torsion. This behavior appears to be very different according to the site and/or the seismicity contexts, as previous studies reported other features (e.g., Yin et al. 2016).

The availability of previous studies that used array processing to determine the proportions of the Love- and Rayleigh-wave energies within the whole seismic energy (Imtiaz 2015; Imtiaz et al. 2017) and were carried out on the translational array data recorded for the two studied sites (i.e., rock, soft-soil), provided the opportunity to compare the Love-to-Rayleigh energy ratios as a function of the frequency determined by the arrays on the one hand and determined by the rotation sensors on the other. The results from both of these approaches are comparable, and they confirm a clearly higher content of Love waves on the soft-soil site in comparison with the rock site, whereas the proportion of energy carried by Rayleigh waves is comparable for both sites.

The coupling of translational and rotational measurements to obtain the 6-DOF signals appears to be a useful approach, not only for direct earthquake engineering applications, but also to study the wavefield composition, while avoiding the need for the deployment of dense arrays, which take longer to install and are more expensive to maintain. However, the relatively high level of instrumental noise for the rotation sensor used in the present study only allowed the recording of moderately strong ground motions (beyond $5 \mathrm{~mm} / \mathrm{s}^{2}$ ). This was possible for Kefalonia Island due to the very rich aftershock sequences of the two early $2014 M_{\mathrm{W}}=6.0$ and $M_{\mathrm{W}}=5.9$ earthquakes. The availability of low-noise rotation sensors, which are easy to deploy in the field, will be of a great interest and should generalize the use of rotation sensors (i.e., the possibility of ambient vibration measurements) and enlarge their possible applications.

\footnotetext{
Authors' contributions

AM was in charge of field measurements and data collection. VP realized the preparation of the database. SS realized all data processing and analysis presented in this paper, and she prepared figures and contributed to the writing of the manuscript. Al realized the wavefield characteristics analysis. $\mathrm{FH}$ $V P, A C$, and $A D$ supervised SB within the framework of her training period for her engineer degree in geophysics. PYB and AC ensured the overall scientific supervision of the work and suggested analyses. FH wrote the final manuscript. All authors read and approved the final manuscript.
}

\section{Author details}

${ }^{1}$ CEA, DEN, 13108 St Paul lez Durance, France. ${ }^{2}$ Université Grenoble Alpes, CNRS, IRD, IFSTTAR, ISTerre, 38000 Grenoble, France. ${ }^{3}$ Bureau de Recherches Géologiques et Minières (BRGM), 45100 Orléans, France. ${ }^{4}$ Université de Strasbourg, CNRS, IPGS UMR7516, 67084 Strasbourg, France.

\section{Acknowledgements}

This study was carried out under the SINAPS@ project that receives French funding managed by the French National Research Agency under the program "Future Investments" (SINAPS@ reference: ANR-11-RSNR-0022).SINAPS@ is a "Seism Institute" project (http://www.institut-seism.fr/en/). The authors would like to thank Cécile Cornou for her help in the coordination with the "French Post-Seismic unit" and "SISMOB/INSU" instrumentation mobile pool (SISMOB is member of RESIF network, a national Research Infrastructure recognized as such by the French Ministry of higher education and research). We would like to thank Jianming Yin for providing us with his rotation data for comparison, and also Ch. Andreou (TEI), R. Cottereau (CentraleSupélec) CNRS), M. Cushing (IRSN), A. Frau (CEA), S. Hok (IRSN), A. Konidaris (TEI), Ph. Langlaude (CEREMA), A. Laurendeau (CEA), A. Savvaidis (EPPO-ITSAK), A. Svay (CentraleSupélec), and N. Theodoulidis (EPPO-ITSAK) for their contribution to the field work. C. Berrie provided valuable correction of the manuscript. Finally, we acknowledge $\mathrm{H}$. Igel and an anonymous reviewer for the constructive comments which greatly helped us to improve our manuscript.

\section{Competing interests}

The authors declare that they have no competing interests.

\section{Availability of data and materials}

The datasets presented in this paper are open and can be uploaded from this Web site: http://argonet-kefalonia.org/data/postseismic_event_data. Please cite the present paper and Perron et al. (2017) if you use these datasets. If there is any need to use the raw data for a specific research project, please contact the second author.

\section{Publisher's Note}

Springer Nature remains neutral with regard to jurisdictional claims in published maps and institutional affiliations.

Received: 31 March 2017 Accepted: 28 August 2017

Published online: 11 September 2017

\section{References}

Bard P-Y (2008) Foreword: the H/N technique: capabilities and limitations based on the results of the SESAME project. Bull Earthq Eng 6:1-2. doi:10.1007/s10518-008-9059-4

Bard P-Y, Bouchon M (1980a) The seismic response of sediment-filled valleys. Part 1. The case of incident SH waves. Bull Seismol Soc Am 70:1263-1286

Bard P-Y, Bouchon M (1980b) The seismic response of sediment-filled valleys. Part 2. The case of incident P and SV waves. Bull Seismol Soc Am 70:1921-1941

Bard P-Y, Bouchon M (1985) The two-dimensional resonance of sediment-filled valleys. Bull Seismol Soc Am 75:519-541

Berge-Thierry C, Svay A, Laurendeau A, Chartier T, Perron V, GuyonnetBenaize C, Kishta E, Cottereau R, Lopez-Caballero F, Hollender F, Richard B, Ragueneau F, Voldoire F, Banci F, Zentner I, Moussallam N, Lancieri M, Bard P-Y, Grange S, Erlicher S, Kotronis P, Le M, Nicolas M, Régnier J, Bonilla F, Theodoulidis N (2016) Toward an integrated seismic risk assessment for nuclear safety improving current French methodologies through the SINAPS@ research project. Nucl Eng Des. doi:10.1016/j. nucengdes.2016.07.004

Bernauer F, Wassermann J, Igel H (2012) Rotational sensors-a comparison of different sensor types. J Seismol 16:595-602. doi:10.1007/ s10950-012-9286-7

Bernauer M, Fichtner A, Igel H (2014) Reducing nonuniqueness in finite source inversion using rotational ground motions. J Geophys Res Solid Earth 119:4860-4875. doi:10.1002/2014JB011042 
Bernauer F, Wassermann J, Frenois A, Krissou R, Bigueur A, Gaillot A, de Toldi E, Ponceau D, Guattari F, Igel H (2017) BlueSeis3A-full characterization of a 3 C broadband rotational ground motion sensor for seismology. In: Geophysical research abstracts, vol 19, EGU2017-15512, EGU General Assembly, Vienna

Cushing EM, Hollender F, Guyonnet-Benaize C, Perron V, Imtiaz A, Svay A, Bard P-Y, Cottereau R, Lopez Caballero F, Theodoulidis N, Moiriat D, Gélis C (2016) Close to the lair of Odysseus Cyclops : the SINAPS@ postseismic campaign and accelerometric network installation on Kefalonia Island—site effect characterization experiment. In: Active Tectonics and Archeoseismology (PATA), Crestone, Colorado, USA

Droste Z, Teisseyre R (1976) Rotational and displacemental components of ground motion as deduced from data of the azimuth system of seismographs. Publ Inst Geophys Pol Acad Sci 97:157-167

Hobiger M, Le Bihan N, Cornou C, Bard P (2012) Multicomponent signal processing for Rayleigh wave ellipticity estimation: application to seismic hazard assessment. IEEE Signal Process Mag 29:29-39. doi:10.1109/ MSP.2012.2184969

Hollender F, Perron V, Imtiaz A, Svay A, Mariscal A, Bard P-Y, Cottereau R, Lopez Caballero F, Cushing EM, Theodoulidis NP, Moiriat D (2015) Close to the lair of Odysseus Cyclops: the SINAPS@ post-seismic campaign and accelerometric network installation on Kefalonia Island. In: Ninth National AFPS Conference. Marne-la-Vallée, France

Igel H, Schreiber U, Flaws A, Schuberth B, Velikoseltsev A, Cochard A (2005) Rotational motions induced by the M8.1 Tokachi-oki earthquake, September 25, 2003. Geophys Res Lett. doi:10.1029/2004GL022336

Igel H, Cochard A, Wassermann J, Flaws A, Schreiber U, Velikoseltsev A, Pham Dinh N (2007) Broad-band observations of earthquakeinduced rotational ground motions. Geophys J Int 168:182-196. doi:10.1111/j.1365-246X.2006.03146.X

Igel H, Brokesova J, Evans J, Zembaty Z (2012) Advances in rotational seismology: instrumentation, theory, observations, and engineering. J Seismol 16:571-572. doi:10.1007/s10950-012-9307-6

Imtiaz A (2015) Seismic wave field, spatial variability and coherency of ground motion over short distances: near source and alluvial valley effects. Ph.D. thesis. Grenoble Alpes University, France

Imtiaz A, Perron V, Svay A, Hollender F, Bard P-Y, Theodoulidis NP (2017) Wavefield characteristics and coherency of seismic ground motion from a rock site at Argostoli Greece (paper \#1743). In: Proceedings of the 16th World conference on earthquake engineering, Santiago, Chile

Konno K, Ohmachi T (1998) Ground-motion characteristics estimated from spectral ratio between horizontal and vertical components of microtremor. Bull Seismol Soc Am 88:228-241

Kurrle D, Igel H, Ferreira AMG, Wassermann J, Schreiber U (2010) Can we estimate local Love wave dispersion properties from collocated amplitude measurements of translations and rotations? Geophys Res Lett 37(4). doi: 10.1029/2009GL042215

Lee WHK, Celebi M, Todorovska MI, Igel H (2009a) Introduction to the special issue on rotational seismology and engineering applications. Bull Seismol Soc Am 99:945-957. doi:10.1785/0120080344

Lee WHK, Huang B-S, Langston CA, Lin C-J, Liu C-C, Shin T-C, Teng T-L, Wu C-F (2009b) Review: progress in rotational ground-motion observations from explosions and local earthquakes in Taiwan. Bull Seismol Soc Am 99:958-967. doi:10.1785/0120080205

Leugoud R, Kharlamov A (2012) Second generation of a rotational electrochemical seismometer using magnetohydrodynamic technology. J Seismol 16:587-593. doi:10.1007/s10950-012-9290-y

Liu CC, Huang BS, Lee WHK, Lin C-J (2009) Observing rotational and translational ground motions at the HGSD station in Taiwan from 2007 to 2008 . Bull Seismol Soc Am 99:1228-1236 doi:10.1785/0120080156

Louvari E, Kiratzi A, Papazachos C (1999) The Cephalonia transform fault and its extension to western Lefkada Island (Greece). Tectonophysics 308:223236. doi:10.1016/S0040-1951(99)00078-5
Marano S, Fah D (2014) Processing of translational and rotational motions of surface waves: performance analysis and applications to single sensor and to array measurements. Geophys J Int 196:317-339. doi:10.1093/gji/ ggt187

Maufroy E, Chaljub E, Hollender F, Kristek J, Moczo P, Klin P, Priolo E, Iwaki A, Iwata T, Etienne V, De Martin F, Theodoulidis NP, Manakou M, GuyonnetBenaize C, Pitilakis K, Bard P-Y (2015) Earthquake ground motion in the Mygdonian basin, Greece: the E2VP verification and validation of 3D numerical simulation up to $4 \mathrm{~Hz}$. Bull Seismol Soc Am 105:1398-1418. doi:10.1785/0120140228

Nakamura Y (1989) A method for dynamic characteristics estimation of subsurface using microtremor on the ground surface. Railw Tech Res Inst Q Rep 30(1):25-33

Nigbor RL (1994) Six-degree-of-freedom ground-motion measurement. Bull Seismol Soc Am 84:1665-1669

Nogoshi M, Igarashi T (1971) On the amplitude characteristics of microtremor (part 2). J Seismol Soc Jpn 24:26-40

Perron V, Hollender F, Mariscal A, Theodoulidis N, Andreou C, Bard P, Cornou C, Cottereau R, Cushing EM, Frau A, Hok S, Konidaris A, Langlaude P, Laurendeau A, Savvaidis A, Svay A (2017) Accelerometer, velocimeter dense-array, and rotation sensor datasets from the Sinaps@post-seismic survey (Cephalonia 2014-2015 aftershock sequence). Seismol Res Lett 0:0-0 (moderate revision)

Pham ND, Igel H, Wassermann J, Kaser M, de la Puente J, Schreiber U (2009) Observations and modeling of rotational signals in the P coda: constraints on crustal scattering. Bull Seismol Soc Am 99:1315-1332. doi:10.1785/0120080101

Richter CF (1958) Elementary seismology. WH Freeman and Company, San Francisco

Spudich P, Fletcher JB (2008) Observation and prediction of dynamic ground strains, tilts, and torsions caused by the Mw 6.0 2004 Parkfield, California, earthquake and aftershocks, derived from UPSAR array observations. Bull Seismol Soc Am 98:1898-1914. doi:10.1785/0120070157

Spudich P, Steck LK, Hellweg M, Fletcher JB, Baker LM (1995) Transient stresses at parkfield, California, produced by the M 7.4 Landers earthquake of June 28, 1992: observations from the UPSAR dense seismograph array. J Geophys Res Solid Earth 100:675-690

Svay A, Perron V, Imtiaz A, Zentner I, Cottereau R, Clouteau D, Bard P-Y, Hollender F, Lopez-Caballero F (2017) Spatial coherency analysis of seismic ground motions from a rock site dense array implemented during the Kefalonia 2014 aftershock sequence. Earthquake Eng Struct Dyn 46(12): 1895-1917. doi:10.1002/eqe.2881

Takeo M (1998) Ground rotational motions recorded in near-source region of earthquakes. Geophys Res Lett 25:789-792. doi:10.1029/98GL00511

Takeo M (2009) Rotational motions observed during an earthquake swarm in April 1998 off-shore Ito, Japan. Bull Seismol Soc Am 99:1457-1467. doi:10.1785/0120080173

Takeo M, Ito HM (1997) What can be learned from rotational motions excited by earthquakes? Geophys J Int 129:319-329

Wassermann J, Lehndorfer S, Igel H, Schreiber U (2009) Performance test of a commercial rotational motions sensor. Bull Seismol Soc Am 99:1449_ 1456. doi:10.1785/0120080157

Yin J, Nigbor RL, Chen Q, Steidl J (2016) Engineering analysis of measured rotational ground motions at GVDA. Soil Dyn Earthq Eng 87:125-137. doi:10.1016/j.soildyn.2016.05.007

Zembaty Z, Mutke G, Nawrocki D, Bobra P (2017) Rotational ground-motion records from induced seismic events. Seismol Res Lett 88:13-22. doi:10.1785/0220160131 